\title{
Switching Costs and Competition in Retirement Investment*
}

\author{
Fernando Luco \\ Department of Economics \\ Northwestern University
}

December 19th, 2013

Job Market Paper

\begin{abstract}
In many markets, such as retirement investment and health care, policy makers are concerned about switching costs because they often distort prices and stand in the way of efficiency. However, we know little about what causes switching costs in actual settings, and how they affect an heterogeneous population of consumers. This paper studies the competitive and policy implications of identifying coexisting switching costs that affect retirement-investment choices in a defined-contribution pension system. To do so, I identify the impact of two sources of switching costs: the need to analyze financial information, which creates decision costs, and the bureaucratic process of switching pension funds, which creates enrollment costs. I use a structural choice model to quantify the magnitude of each switching cost, and to estimate preferences over pension funds. Then, I embed the choice model in a dynamic pricing game to study how policies that target a single switching cost affect consumer behavior, welfare, and competition. Two important results follow from the analysis. First, decision costs are, on average, twice as large as enrollment costs, though there is significant heterogeneity across the population. Second, eliminating decision costs increases consumer welfare by $8 \%$ more than eliminating both switching costs. Both of these results illustrate the importance of distinguishing between coexisting switching costs.
\end{abstract}

${ }^{*}$ I am especially grateful to Igal Hendel for his guidance and generosity. I am also grateful to Robert Porter and Aviv Nevo for their help and support. I thank Iván Canay, John Friedman, Matthew Gentzkow, Ben Handel, Manuel Hermosilla, Garrett Johnson, Christopher Lau, Robin Lee, Lee Lockwood, Guillermo Marshall, Ken Onishi, Álvaro Parra, Tiago Pires, Mike Powell, Alberto Salvo, Kosuke Uetake, and Zenon Zabinski for helpful comments and suggestions, and participants in the Applied Micro Reading Group and the Industrial Organization seminar at Northwestern University for their feedback. E-mail: fluco@u.northwestern.edu All errors are my own. For the latest version of this paper, visit http://gradstudents.wcas.northwestern.edu/ efl891/indexjm.html 


\section{Introduction}

In many markets, such as retirement investment and health care, consumers stick to their decisions even when their economic environment changes significantly. Economists refer to this behavior as 'inertia,' and often explain it as a consequence of switching costs deterring consumers from switching to alternative options. Because switching costs generally result in high equilibrium prices and efficiency loss (see Farrell and Klemperer, 2007), they have been studied for decades. To this day, however, two main features of switching costs make it difficult to study them. First, we know little about the sources of switching costs in actual settings. Second, multiple switching costs may coexist (i.e., transaction costs, psychological costs, cost of time, and penalty fees). For these reasons, it is challenging to design policies to reduce switching costs and their negative consequences.

I study inertia in retirement-investment choices in the Chilean defined-contribution pension system (see Section 2 for more details about the Chilean pension system). Because of its institutional characteristics, the Chilean system allows me to separately identify two coexisting switching costs: the cost associated with analyzing financial information required to choose a pension fund ('decision cost,' henceforth), and a hassle cost in the form of a time-consuming bureaucratic process that enrollees have to follow when switching pension funds ('enrollment cost').

In this context, this paper makes three contributions. The first contribution is to document the existence of significant inertia in retirement-investment choices. I show that over a period of fourteen years (1988-2001), 55\% of the people in my sample did not switch pension funds, despite significant changes in the economic environment. This suggests the presence of significant switching costs. The second contribution is to measure the relative magnitude of the coexisting switching costs. I find that decision costs are, on average, twice as large as enrollment costs, though there is significant heterogeneity across consumers. The third contribution is to show that distinguishing between coexisting switching costs can be critical for the effectiveness of policy. Indeed, I find that eliminating decision costs increases consumer welfare by $8 \%$ more than eliminating both decision and enrollment costs. This result, though counterintuitive, arises because in the presence of small switching costs the incentive to invest in new enrollees (to decrease prices) dominates the incentive to harvest 
existing enrollees (to increase prices), while this strategic effect is not present in the absence of switching costs. This means that when consumers face low switching costs, firms are willing to sacrifice current profits in exchange for those they expect to receive in later periods, which does not happen when switching costs do not exist. On the other hand, when switching costs are large the incentive to harvest dominates the incentive to invest and prices increase.

The identification strategy that I use in this paper relies on institutional features of the Chilean pension system that imply that enrollees belong to one of three groups. The first group, 'existing enrollees,' consists of people who have contributed to their accounts every month for a period of time. Existing enrollees face both decision and enrollment costs when they switch pension-fund administrator ('PFA,' henceforth). The second group, 'returning enrollees,' consists of people who return to the system after a period in which they did not contribute to their accounts. This group faces enrollment costs regardless of whether they want to switch PFAs or not. This happens because, as people only save and pay fees when employed, and both fees and savings are proportional to income, their change in status has to be registered even if they decide to remain enrolled with their current PFA (see Section 2 for more details). As a consequence, enrollment costs cannot affect their decisions. However, decision costs may induce them to remain enrolled with their current PFAs. For this reason, comparing choices by existing and returning enrollees identifies enrollment costs. The third group, 'new enrollees,' consists of people who are entering the system for the first time. Because there is no default option for new enrollees, they have to choose and enroll with a PFA. For this group both costs are unavoidable. Therefore, comparing the decisions of new and returning enrollees identifies decision costs (see Section 3.1 for more details).

To study the impact of the different switching costs on consumer behavior and competition, I proceed in three steps that combine descriptive exercises and structural analysis. In the first step of the analysis I use descriptive exercises to show that inertia is significant and costly. In addition, I show that the different groups of enrollees behave according to the switching costs they face (see Section 3). As mentioned above, $55 \%$ of the enrollees in my data never switched pension funds. Moreover, the average overpayment rate, relative to the cheapest option of the choice set, is $16 \%$ (which increases to $19 \%$ for people who never 
switched). This means that, because of passive behavior, the average enrollee overpays by the equivalent of two months of fees per year, or $0.5 \%$ of income. I also provide evidence supporting the hypothesis that decisions of returning enrollees are only affected by decision costs, and not by enrollment costs. In particular, returning enrollees are significantly more likely to switch PFAs than existing enrollees, even when controlling for a rich set of demographic information. Moreover, conditional on switching, all enrollees make similar choices. This suggests that the only relevant difference across these groups of enrollees is, in fact, the switching costs they face (see Section 3).

The second step of the analysis is to quantify each switching cost and to estimate preferences over pension funds. To do so, I propose a model that allows for both observed and unobserved heterogeneity in switching costs and preferences. To model observed heterogeneity, I exploit the richness of my data, which includes detailed demographic information for every enrollee in my sample (see Section 4). The results, reported in Section 5, show that inertia is mostly explained by decision costs, which account, on average, for 70 to $80 \%$ of the total cost faced by enrollees. There is, however, significant heterogeneity across enrollees. This finding adds to the existing literature that shows that people may avoid making decisions that involve analyzing complex information (see Madrian and Shea, 2001; Choi, Laibson and Madrian, 2009; Beshears et al., 2013; Thaler and Sunstein, 2008, and the references therein), but it also goes beyond this literature by quantifying the magnitude of the underlying switching costs. This is particularly relevant for policy makers, because it suggests that policies that are targeted at the decision cost may have greater impact on consumer behavior than policies targeted at the decision cost. In addition, policies must consider that enrollees face different sources of switching costs. Indeed, a policy that eliminates enrollment costs, that only affect existing enrollees, and, on average, account for $30 \%$ of total costs, is not equivalent to a policy that eliminates $30 \%$ of total costs by reducing decision costs, because decision costs affect both existing and returning enrollees.

The third step of the analysis is to study whether distinguishing between coexisting switching costs is important for the effectiveness of policy. To do so, I propose a dynamic pricing model in which PFAs compete for enrollees by choosing fees (see Section 6). I apply the model to a variety of settings, which are determined by the policies under study. 
I consider policies that either eliminate decision costs (e.g., delegated management and personalized information), or enrollment costs (e.g., online enrollment). In addition, I study how the introduction of a mandatory default option, that assigns new enrollees to the cheapest PFA in the market, affects competition among pension funds. This last policy, similar to one that was introduced in Chile in 2009, differs from the first two, which focus on eliminating switching costs. Nonetheless, it is interesting because the data show that new enrollees, as well as existing and returning ones, do not choose options with the lowest available fees. Hence, policies such as this one guarantee that, at least for a period, enrollees are locked-in with the cheapest PFA, and if switching costs are high, they will switch to high-fee funds with low probability.

Two main results highlight the importance of distinguishing between switching costs. First, eliminating decision costs increases total welfare three times more than eliminating enrollment costs. Second, and more importantly, eliminating decision costs increases consumer welfare by $8 \%$ more than when eliminating all sources of inertia. This result, though counterintuitive, follows because in the presence of low switching costs the incentive to invest in new enrollees dominates the incentive to harvest existing enrollees, intensifying price competition and driving prices below those that would result from eliminating all switching costs. This means that, when switching costs are low, firms sacrifice current profits in exchange for future profits, and prices decrease below those obtained in the absence of switching costs. This strategic effect of switching costs on prices is absent when switching costs do not exist, because firms are not willing to sacrifice current profits if consumers will switch away in the future when a firm increases its price. Finally, this effect is reversed when switching costs are high because switching is infrequent and, hence, firms are better off harvesting their captive consumers. These results also show that what ultimately determines equilibrium prices is not only the relative magnitude of the different costs, but also the share of the population that is affected by each of them. Indeed, eliminating decision costs has a larger impact both because of the relative magnitude of these costs and because they affect returning and existing enrollees, while enrollment costs affect only existing enrollees. Note, however, that because participation is mandatory, there is no quantity distortion. This means that the increase in consumer welfare due to the competitive effect of decreas- 
ing switching costs, cancels out with the lower profits perceived by pension funds. This, in turn, means that the change in total welfare is only driven by lower switching costs. As switching costs are, by definition, zero when all switching costs, this increases total welfare by $4 \%$ more than when only decision costs are eliminated.

Finally, Section 6 also shows that the impact of regulation that introduces a mandatory default option depends on the distribution of market shares. When firms start a period with equal market shares, the introduction of a mandatory default option intensifies price competition and reduces equilibrium fees. Instead, when market shares differ, the dominant firm focuses on harvesting its existing enrollees. This, in turn, allows a firm with a small market share to charge a higher fee than what it would charge in the absence of such a regulation.

This paper contributes to three strands in the literature. The first studies pricing implications of switching costs. The theoretical literature on switching cost and prices has shown that in the presence of switching costs prices can either increase (Klemperer, $1987 a$, b; Beggs and Klemperer, 1992) or decrease (Arie and Grieco, 2012; Cabral, 2013). For this reason, the impact of switching costs on prices has become a matter of empirical investigation. Nonetheless, this type of work is scarce. Farrell and Klemperer (2007) survey the empirical literature on switching costs and emphasize the importance of observing initial choices to separately identify switching costs from unobserved heterogeneity. As it is difficult to find datasets that satisfy this condition, few authors have been successful in separately identifying switching costs and preferences. This paper falls within the few that have been able to separately identify switching costs and preferences. In addition, to the best of my knowledge, this paper is the first to identify coexisting switching costs and study the competitive implications of policies that target them. In this sense, few papers have tried to distinguish between sources of inertic behavior. Miravete and Palacios-Huerta (forthcoming) distinguish between inattention, state dependence, and learning in the context of telephone contracts. Hortaçsu, Madanizadeh and Puller (2011), using a model similar to the one that I present in Appendix $\mathrm{A}$, distinguish between incumbency advantage (vertical differentiation), search costs, and switching costs in the context of retail electricity markets. In contrast, I focus on studying the impact of different switching costs on 
competition. In terms of modeling assumptions, Handel (2013) is the closest to this paper. He studies the role of inertia in choosing health insurance, and observes active and inactive choices for every enrollee in his sample. He shows that single enrollees forgo $\$ 2,000$ annually because of inertia, even though there is no price competition in his setting. Though both of us model consumer behavior in a similar way, we differ in that this paper decomposes switching costs into its components. Dubé. Hitsch and Rossi (2009) study the impact of switching costs on steady state prices of two consumption goods, orange juice and margarine. They conclude that, in the context of their data, switching costs resulted in lower equilibrium prices than they would be if these costs did not exist. Finally, there are also studies that investigate the impact of inertia without quantifying its value (e.g., Ericson, 2012 in health insurance, and Crawford. Tosini and Waehrer, 2011 in telephone contracts).

The second strand of the literature studies investment choices in the context of 401(k) plans in the United States. This literature studies how plan design affects participation rates, asset allocation, and contribution rates. This literature is related to this paper because it shows how policy (plan design) affects people's behavior in the context of private pension systems. In addition, this literature documents the existence of inertia, but it does not quantify switching costs or its components. Madrian and Shea (2001) and Carroll et al. (2009) show that automatic enrollment increases participation as well as the fraction of people who choose default options. In a similar setting, Chetty et al. (2012) show that policies that require active decisions by enrollees, such as systems based on tax subsidies, are less effective in increasing total savings than those that do not, such as automatic employer contributions. Finally, Beshears et al. (2011) and Choi, Laibson and Madrian (2011) show that providing information to enrollees has little impact on their choices, suggesting that in the context of this paper delegated management may be more effective in reducing decision costs than personalized information.

Finally, the third strand of the literature studies investment choices in the context of the Chilean and Mexican defined-contribution pension systems. This literature has focused on studying how information and the way in which prices are expressed affects choices, but it has neither studied the impact of inertia on choices, nor its implications on equilibrium pricing. Thus, although the systems and data are similar to those of this paper, the questions 
analyzed are quite different. Duarte and Hastings (2009) study Mexico, where government intervention shifted consumers' and firms' attention from multiple fees to a single fee index. Hastings (2010) shows evidence of heterogeneity in the weights people put on past performance and fees. Hastings and Tejeda-Ashton (2008) and Hastings, Mitchell and Chyn (2010) show that the way in which fees are presented has significant impact on choices. Finally, Hastings. Hortacsu and Syverson (2013) show that people in Mexico showed low price elasticities but were sensitive to advertisement, resulting in pension funds competing in advertisement rather than in fees. ${ }^{1}$

\section{The Chilean System}

\section{$2.1 \quad$ Institutional details}

Chile reformed its pension system in 1981, switching from a pay-as-you-go system to a defined-contribution system. Prior to this change, the Chilean system consisted of multiple providers that collected resources from contributors and paid to retirees. During this period the contribution rate was high and the level of pensions depended on the provider with which an investor was enrolled. In addition, there was significant uncertainty about whether the system would be able to meet its payments. ${ }^{2}$

Between 1981 and 1983, people who entered the labor force could choose whether to enroll in the old system or the new one. Fees in the new system were half of those charged in the old system, thus giving incentives to enroll in it. Starting in 1983, it was mandatory for new enrollees to participate in the new system, and the state recognized past contributions made to the old system by enrollees who switched to the new one. In addition, since 1981, the contribution rate has been equal to $10 \%$ of income. Finally, until 2010, new enrollees did not have a default option at the moment of enrollment and were thus required to choose a PFA whether they wanted to do so or not. On the other hand, people who returned to

\footnotetext{
${ }^{1}$ There is a broad body of literature that estimates demand functions for PFAs in reduced form using Chilean data (Bernstein and Micco, 2002; Bernstein and Ruiz, 2004; Marinovic and Valdés, 2005; Bernstein and Cabrita, 2006; Cerda, 2005). The approach employed by these papers is quite different from the one followed in the present paper and by the literature described above.

${ }^{2}$ See Ferreiro (2003) for a comprehensive description of the Chilean pay-as-you-go system.
} 
the system could remain with the PFA with whom they were enrolled before they left.

Participation in the new system is mandatory for those employed in the formal sector. Workers contribute to their own private pension accounts and choose a PFA. Entry, exit, and mergers of PFAs, as well as the type of financial assets in which they could invest, has always been regulated. Finally, PFAs operate across the country because the market is defined at the national level.

In 1988 there were twelve PFAs. Figure 1(a) shows that the number of PFAs increased slowly between 1988 and 1992 and then sharply between 1993 and 1994 . The number of PFAs decreased significantly between 1995 and 2001, mainly because of mergers, though in some cases PFAs failed to meet regulatory requirements and were forced to leave the market.

PFAs can freely choose the level of fees they charge, though price discrimination is not allowed. Between 1981 and 1987, PFAs were allowed to charge fees on the balance of the accounts as well as on the contribution flow. This changed in 1988, and since then PFAs can only charge fees on contribution flows. Between 1988 and 2008, PFAs either charged a percentage fee over income or the percentage fee plus a fixed fee. Figure 1(b) shows the evolution over time of the mean fixed fee in the left axis and the mean percentage fee in the right axis. The fixed fee is reported in U.S. dollars of December 2001, though all estimation is done in Chilean pesos of the same year. Finally, figures 2(a) and 2(b) show the evolution of quartiles of fees over time. The figures show that at any point in time there was significant dispersion of both fixed and percentage fees, suggesting that inertia may result in suboptimal choices even for people who choose to minimize fees when enrolling.

Between 1981 and 2001, each PFA offered only one investment product. Every month, PFAs took all new contributions and existing balances, and invested these resources in different financial assets. Though investment limits have changed over time, there has always been a limit on fractions of portfolios allocated to risky assets by type and by origin. Table 2 compares investment limits in 1989 and 1999.

Chilean regulations limit enrollees' exposure to risk. In particular, regulation require PFAs with returns of $2 \%$ or more below the industry mean to cover the losses with their own capital. In addition, if returns are $2 \%$ or more above the industry mean, the excess 
returns are saved to cover losses in case the lower bound is reached. This results in PFAs having strong incentives to mimic each other, and as a consequence there is little variation in returns (figure 33).

Since October 2002, PFAs have been able to offer up to five different investment alternatives targeted to different age groups and risk preferences. Because my data do not allow me to identify in which product and with which PFA a contributor is enrolled, and because people can choose up to two investment alternatives, I study investor behavior between 1988 and 2001.

As described in this section, the Chilean system shares many similarities with the $401(\mathrm{k})$ of the U.S., though there are a number of important differences. First, in the Chilean system participation is mandatory for people who work in the formal sector. Second, the Chilean market covers the whole country and everybody faces the same choice set and fees. Finally, until 2002 enrollees could only choose a PFA, but not asset allocation. Starting in 2002, as PFAs were allowed to offer up to five investment funds, enrollees were allowed to divide their balance in up to two of this alternatives within a PFA. For these reasons, from the perspective of its enrollees, the Chilean system could be perceived as simpler than the 401(k) system, which has the benefit of allowing for a cleaner identification of sources of switching costs. On the other hand, this makes estimates of switching costs in this system a lower bound for those that could be obtained in more complex environments.

\subsection{Data}

This paper uses an administrative dataset provided by the Chilean supervisor, Superintendencia de Pensiones. ${ }^{3}$ The dataset is a panel of individual histories that starts in 1981 and contains information for 24,662 people from their enrollment date until either 2009 or the time of their last contribution. For each person I observe when they contributed and paid fees to their chosen PFA. The dataset consists of a random sample of Chileans and was generated in 2002 by the government. The individual histories of contributions were re-created by the supervisor using administrative records of the PFAs.

\footnotetext{
${ }^{3}$ Though the role of the Superintendencia de Pensiones is that of a regulator, the English version of its website refers to it as 'Supervisor'.
} 
In this paper I use a sample of people for which I observe initial choices and was able to match to PFAs. I first dropped all people who participated in the old pension system because they might have been affected by the transition period. The voluntary nature of their move from the old system to the new one, makes them different from those who entered the system later and did not have the opportunity to make a voluntary decision.

Second, the fee schedule used before 1988, that allowed PFAs to charge fees on the balance and on contribution flows, generated a number of inconsistent matches between people and PFAs, forcing me to drop all those who entered the system between 1981 and 1987.

Finally, I dropped all the data following 2001. As mentioned previously, in 2002 PFAs could begin to offer up to five investment funds for which they charge a common price. Including this data would eliminate the possibility of unambiguously assigning people to funds. The final sample consists of 350,660 observations from 8,888 people who enrolled between 1988 and 2001.

For each person the dataset has information on income and fees paid at the time of each contribution, and characteristics such as gender, birth and enrollment dates, and whether they opened a voluntary savings account to save additional resources for retirement.

As described above, the main characteristics of the Chilean pension system are that participation is mandatory for people who work in the formal sector, that PFAs serve the entire country, and that prices are non-discriminatory. For this reason, not only is the choice set the same for all people in the country, but also the fees charged and the returns obtained. For each month, I observe the choice set, the fees charged by all PFAs, and any mergers that might have occurred. I also observe the daily returns of the portfolios managed by each PFA, though not their composition. Given the consumer level data available, I focus on monthly returns and in the analysis I use average annual real returns computed over 36 months as measure of past performance.

Table 3 reports the summary statistics of the final sample after dropping people that were impossible to assign to any PFA at some point in time. The table shows that $50 \%$ of the people in the estimation sample are female with a mean enrollment age of $25.16 \%$ of the people in the sample opened a voluntary savings account, and the average monthly income 
is $222,552.4$ Chilean pesos of 2001 that correspond to 332.6 U.S. dollars of December 2001. Finally, of the 350,660 observations, 12,196 correspond to people switching PFAs $(3.5 \%$ of all observations), while 43,648 correspond to active decisions by people who return to the system after periods without contributions (12.4\% of all observations).

\section{$3 \quad$ Preliminary Evidence}

This section provides evidence supporting an intuitive prediction: if returning enrollees only face decisions costs, while existing enrollees face both decision and enrollment costs, returning enrollees should switch more. In this section I show evidence for this, though more evidence is provided in Luco (2013).

\subsection{Returning enrollees have a higher probability of switching}

Figure 4 shows the distribution of the number of times people switched PFAs between 1988 and 2001. Switching is not a common phenomenon. Indeed, $55 \%$ of the people in the sample never switched pension funds, though there is significant variation across people.

Given that people do not switch often, when do they switch? If decisions by returning enrollees are only affected by decision costs, and those of existing enrollees are affected by decision and enrollment costs, then returning enrollees should switch more. Table 4 shows that $40 \%$ of changes of PFAs are associated with people who return to the system, which in turn represent $12.4 \%$ of the number of observations in the sample. This means that $10.9 \%$ of observations from returning enrollees involve switching PFAs. In the case of existing enrollees this number decreases to $2.5 \%$. When restricted to people who also have a voluntary savings account, both numbers increase to $15 \%$ and $3.3 \%$.

The evidence just described shows that returning enrollees behave as if they have lower switching costs than existing enrollees. However, this evidence does not take into account other factors that may also affect the switching decision. For example, changes in income may also induce switching because of the fee structure (a fixed fee plus a percentage fee charged over income). If an enrollee's income increases significantly then she might decide to switch from her current PFA to a PFA with a lower percentage fee and higher fixed fee. 
For this reason, if an enrollee is both returning to the system and receiving higher wages than in her previous job, the effect of returning to the system would be overestimated if we do not control for the change in income.

To take this into account I estimate several probit regressions with different sets of regressors and fixed effects. The dependent variable is equal to one if the enrollee switched PFA in that period and zero otherwise, while the independent variables change across columns. The results are reported in table 5. In all specifications standard errors are clustered at the individual level, and an observation is an individual-month combination.

The first specification includes only the indicator that is equal to one if the enrollee was a returning enrollee in that month. The effect of returning is both positive and highly significant. The estimated coefficient implies a $10.93 \%$ higher probability of switching than in the case of an existing enrollee. The second column replaces the indicator for returning with an indicator that is equal to one if the enrollee had an increased in income of $10 \%$ or more, relative to her average income of the last five months in which she was an existing enrollee. The result, though positive and significant, disappears once we add the indicator for a returning enrollee (column three). Column four adds year fixed effects and show that the previous results are robust to changes in specification. Column five adds demographic information. It shows that older people switch less (see also figure 5(a), that high-income people switch more (figure 5(b)], and that gender is irrelevant. The marginal effect increases slightly with respect to the first specification, reaching 10.59\%. Finally, column six adds PFA fixed effects and shows that the results are robust to PFA-specific characteristics. Here, the marginal effect of returning increases to 10.7\%. Overall, these regressions suggest that the probability of switching PFAs is mostly affected by returning to the system rather than other individual characteristics. For this reason, the results also suggest that when returning, the level of switching costs is lower than the level faced by existing enrollees, because those faced by returning enrollees are partially sunk. ${ }^{4}$

Two assumptions across all these regressions are that returning and existing enrollees are

\footnotetext{
${ }^{4}$ Though not reported here, the results are robust to controlling for other variables such as income level, savings levels, and the time elapsed before returning to the system. Across all these specifications the marginal effect of returning to the system ranges between 9.32 and $10.83 \%$.
} 
similar, and that there is no selection into these groups. These assumptions are valid as long as people switch groups randomly and not because they would face fewer sources of switching costs. Though it is not possible to guarantee random assignment, two arguments suggest that selection is not an issue. First, people are classified as returning when they go back to the system after periods without contributing. This is likely to be the case either because they leave unemployment, or go from self-employment (or informal employment) to formal employment. As long as these transitions are not motivated by a desire to switch PFAs, selection is not a concern. Second, as people transition from returning to existing enrollees from one month to the next, the distributions of observable characteristics across groups are similar. This is shown in figure 7. With the exception of age, which is mechanically lower for new enrollees, the figures show that the distribution of observables are similar across groups. If unobservable characteristics are correlated with observable characteristics, then selection is not an issue.

\subsection{People who switch more pay less, though nobody beats the market}

To study whether there are benefits from switching PFAs, I now focus on how fees and returns vary with the number of times people switch. Figures 6(a) and 6(b) plot fees paid relative to the cheapest alternative and returns obtained for the three years after switching, as a function of the number of times people switched PFA. Also, table 6 reports the mean of each of these variables, and distinguishes between people based on whether they had a voluntary savings account. Though the relationship between fees and number of changes is negative, it is clear that people do not minimize fees. This is true even for those who switch often (see Choi. Laibson and Madrian, 2010, for similar results in the mutual fund industry). In particular, the average overpayment rate, without conditioning on the number of changes, is $16 \%$, which increases to $19 \%$ for people who never switched. At the mean level of income and fees, this means that the average enrollee overpays by the equivalent of two months of fees per year, or $0.5 \%$ of income. If the average enrollee were to save these resources in addition to the mandatory savings, her account balance would increase by $5 \% .^{5}$

\footnotetext{
${ }^{5}$ These calculations consider a person whose lifetime income is the average income as reported in table 3 and pays a fixed fee equivalent to $\$ 0.5$ U.S. dollars and a percentage fee of $3.2 \%$ of income. The rate of
} 
In the case of returns, the figure shows that they do not differ depending on the number of times people switch, which is consistent with the little dispersion of returns observed in figure 3 .

\subsection{Conditional on Switching, Everybody Pays the Same}

A natural concern about different groups is that they might also capture other differences beyond the different switching costs each group faces. In order to test whether this is the case or just the different switching costs matter, I regress excess payments on group identifiers and different sets of fixed effects, conditional on people either switching or entering the system. As in both cases all switching costs are irrelevant for the decision making, one would expect all groups to behave similarly. The results, reported in table 7, show that, after controlling for PFA fixed effects, this is, indeed, the case. This suggests that differences across groups are generated by the different switching costs they face rather than unobservables. This also suggests that including PFA fixed effects to capture PFA characteristics that are unobserved to the econometrician, is important in explaining the data.

Altogether when considering what determines the probability of switching and the benefits derived from doing so, there is significant heterogeneity across the population. In particular, though changes in contribution status seem to be the most important determinant of switching behavior, changes in age and in income also have a significant role. The demand model that is proposed and estimated in the next section makes use of these, as well as other information, to model consumer heterogeneity in inertia and preferences for product characteristics such as fees and past performance.

return does not affect this calculations as it is the same whether the person saves the additional resources or not. 


\section{Choice model, Identification and Estimation}

\subsection{A model of investor behavior}

In the Chilean system enrollees receive information from several sources. The main source of information are the statements sent out every four months that consist of personalized information about the balance of the account, the fees charged by every PFA in the market, and their past returns for different time periods. Though the way in which statements are designed depends on each PFA, the information they contain is determined by the regulator. In addition, PFAs do advertisement which is also regulated. Additional information is sent out every time a PFA announces changes to its fees or a merger is authorized.

Given the type of information enrollees have, it is likely that their decisions are based on comparing fees, past performance, and any other PFA characteristic they may observe. It is natural then to model behavior following a discrete choice approach, in which enrollees have heterogeneous preferences over fees, past performance, and other PFA characteristics that are unobserved to the econometrician. I also assume that enrollees are myopic in their decision-making, something I discuss at the end of this section. Under this framework, person $i$ 's indirect utility from choosing PFA $j$ in period $t$ can be written as

$u_{i j t}=\alpha_{i t}\left(y_{i t}-0.1 y_{i t}-f_{j t}-p_{j t} \min \left\{y_{i t}, \bar{y}_{t}\right\}\right)+X_{j t}^{\prime} \beta_{i t}-\eta_{i t}\left(Z_{i t}, \theta\right) \mathbb{1}\left\{d_{i t-1} \neq j\right\}+\xi_{j}+\varepsilon_{i j t}$.

In this setting, consumer $i$ chooses fund $j$ if $u_{i j t} \geq u_{i k t}$ for all $k \neq j$.

The different components of the indirect utility function can be classified in two groups. The first group consists of variables that are specific to a PFA, such as fixed fees $f_{j t}$, percentage fees $p_{j t}$, and observable and unobservable characteristics $X_{j t}$ and $\xi_{j}$. The second group consists of individual specific variables. These include demographics $Z_{i t}$ that affect switching costs $\eta_{i t}$, an independent and identically distributed idiosyncratic shock $\varepsilon_{i j t}$, and random coefficients $\alpha_{i t}$ and $\beta_{i t}$. In this specification, $\alpha_{i t}$ corresponds to the marginal utility of income, and the term in parenthesis corresponds to disposable income after saving for retirement and paying fees. In the same way, $\beta$ corresponds to the marginal utility of the observable characteristics included in $X{ }^{6}$

\footnotetext{
${ }^{6}$ Note that fees are bounded above by an upper limit on the maximum income that can be used for such
} 
I model switching costs as those faced when an enrollee chooses a PFA different from the one with whom she was enrolled in the previous period. This specification implicitly assumes that the cost introduced by either the decision or the enrollment process is equivalent to a tangible cost such as a penalty fee, and implies that in order to switch PFAs an enrollee must value the new PFA in at least $\eta$ more than her current PFA. Though this formulation is similar to that used in Handel (2013) and Dubé. Hitsch and Rossi (2009), it differs in that it distinguishes costs that are faced by different types of enrollees. Finally, it is assumed that components of switching costs are independently distributed, conditional on $Z_{i t}$.

Though the model is simple and allows me to specify a rich demand system with flexible substitution patterns, there are important assumptions that must be discussed in detail. First, the assumption of myopic enrollees, though supported by the literature (i.e., see Hastings and Tejeda-Ashton, 2008; Hastings. Mitchell and Chyn, 2010), is not trivial and implies two different assumptions regarding how individuals make decisions. First, it implies that the utility function is defined in reduced form because enrollees derive flow utility from returns of their pension account, even though these payoffs will only be realized when retiring. This, however, is based on the fact that the best prediction that people can make regarding future fees and returns are precisely the ones that they currently observe. Second, I abstract from the fact that people may anticipate that fees may change in the future (but not the direction of these changes) and so, they may decide to stay enrolled in their current PFA to wait until such uncertainty is resolved. In other words, I abstract from the fact that switching costs introduce an option value of waiting. Though this implies that the level of switching costs relative to flow utility may be overestimated, it should not affect the relative magnitude of each switching cost.

A second caveat with respect to the model is that it assumes that existing enrollees face the decision and enrollment costs at the same time. In practice, it is likely that these costs are faced sequentially. If this is the case, modeling the problem as simultaneous will overestimate the decision cost as some enrollees may decide to incur this cost but choose computation. This value changes monthly and is defined as 60 U.F. where U.F. is a monetary unit that is adjusted by inflation, and so, of constant value. Note that though the limit is introduced in the computation of fees, it is not used when specifying random coefficients. 
not to switch. For this reason, in Appendix A I present and estimate a sequential model in which enrollees first decide whether to face decision costs, and then, conditional on facing the decision process, they decide on whether to switch or not. Because the interpretation of each cost changes in this model, I defer discussion to the appendix. That said, it is important to note that there are no qualitative differences in how switching costs are distributed across the population, though the level of them change as it is expected. Both costs are lower in the case of the sequential model, but their relative magnitude does not change. Because there are no other important differences between the two models, I use the simple model in the remainder of the paper.

Finally, as I described above, I model both switching costs as being equivalent to a tangible switching cost, though in practice is likely that only the enrollment costs falls in this category (as a transaction cost), while the decision cost is implicit. This assumption, however, should not have a significant impact on the rest of the parameters to be estimated because, as described in the next section, these parameters are identified from initial choices. In this sense, when discussing the estimated parameters, I show that estimating a model with only initial choices results in qualitatively similar estimates of the random coefficients to those obtained with all the data and considering both sources of switching costs.

\subsection{Identification}

Every paper that estimates switching costs faces a nontrivial identification challenge: switching costs and permanent unobserved consumer heterogeneity are observationally equivalent. To this I add a second challenge: how can switching costs be separated into its components? For clarity I address both challenges separately.

First, recall that I observe all initial choices. The specification of the demand model implies that new enrollees face both costs because they have to choose a PFA and go through the enrollment process. As these costs are independent of the alternatives considered, they cancel out and are irrelevant when comparing alternatives. On the other hand, an existing enrollee only pays both costs when switching. Hence, total switching costs are identified from the different choices of existing and new enrollees. This overcomes the first challenge and is the standard identifying assumption in most of the literature on switching costs. 
The second identification issue involves identifying the components of switching costs. To identify these components, it is necessary to observe people making choices in settings with and without some of the potential components. The ideal setting would be to randomly assign people to different groups, one with all components of switching costs and other groups facing the various combinations of all minus one of them. With the same choice sets and product characteristics, differences in choice behavior would only be determined by the excluded component of switching costs and so, the impact of each component on total inertia would be identified.

In practice we do not observe random assignment into groups. However, under the assumption that when people do not contribute it is because they have been affected by a shock such as unemployment, comparing decisions of "identical" enrollees in different groups identifies decision costs. Thus decision costs are identified by differences in choices between new and returning enrollees, while a similar comparison between existing and returning enrollees identifies enrollment costs. Note that this argument is also valid for people who switch jobs, assuming that such a switching is not driven by a desire to switch PFA. Finally, figure 7 compares the distribution of two observable demographics by groups and show that, though there are some differences, all the distributions are similar across groups. This is driven by changes in status being from one month to another, so exogenous to the switching decision. ${ }^{7}$

Identification of the random coefficients follows standard arguments. In particular, because when choosing for the first time, enrollees have no switching costs, variation in choice sets and prices over time identifies taste coefficients. This argument, however, is slightly different in the case of $\alpha$ than it is in other papers. In particular, it is normally the case that prices do not depend on income. Hence, variation in prices is used to identify

\footnotetext{
${ }^{7}$ Though the arguments described above identify switching costs from permanent (time invariant) unobserved heterogeneity, a final comment may be helpful. If behavior is driven by unobserved heterogeneity that is not correctly controlled for, then one would expect people to switch PFAs following a merger. On the other hand, if enrollees do not switch after the (unexpected) merger, then behavior is driven mostly by switching costs. I observe less than 30 changes of managers in the first month following any merger. When looking at a window of three months before and after the merger, the switching rate is less than five percent. I conclude that it is switching costs, rather than unobserved heterogeneity, that explains choice behavior.
} 
the marginal utility of income. In this case, however, the percentage fee may change, but income may change at the same time, leaving disposable income unchanged. For this reason, I exclude income from the demographics included in the parametrization of $\alpha$. If I were to include income, one could obtain that changes in fees and income, that leave disposable income unchanged, affect the marginal utility of income. To avoid this type of results, I exclude income from the demographics included in the parametrization of $\alpha$.

As initial choices are used to identify $\alpha$ and $\beta$, the remaining choices are used to identify switching costs as explained above. This, however, does not solve the potential problem of endogeneity present in the estimation of discrete choice models, meaning that prices might be correlated with the unobserved component $\xi$. I deal with this potential problem by assuming that unobserved pension fund characteristics do not vary over time and can be incorporated in the estimation through manager fixed effects.

\subsection{Specification and estimation}

To understand how switching costs are quantified and identified it is helpful to write down both, the indirect utility and the choice probability of each group of enrollees. I do this by rewriting the indirect utility function as

$$
\begin{aligned}
u_{i j t} & =-\alpha_{i t}\left(f_{j t}+p_{j t} \min \left\{y_{i t}, \bar{y}_{t}\right\}\right)+X_{j t}^{\prime} \beta_{i t}-\eta_{i t}\left(Z_{i t}, \theta\right) \mathbb{1}\left\{d_{i t-1} \neq j\right\}+\xi_{j}+\varepsilon_{i j t} \\
& =\tilde{u}_{i j t}-\eta_{i t}\left(Z_{i t}, \theta\right) \mathbb{1}\left\{d_{i t-1} \neq j\right\}+\varepsilon_{i j t},
\end{aligned}
$$

where $\tilde{u}_{i}$ contains all determinants of person $i$ 's indirect utility with the exception of switching costs and the idiosyncratic shock. In addition, I assume that $\varepsilon$ is independent and identically distributed Extreme Value Type I.

Assuming for a moment that there are only two PFAs, 1 and 2, the indirect utility of a new enrollee of choosing either of these options is given by

$$
\begin{aligned}
& u_{i 1 t}^{N}=\tilde{u}_{i 1 t}-\overbrace{\left(\eta_{i t}^{D}\left(Z_{i t} ; \theta_{D}\right)+\eta_{i t}^{E}\left(Z_{i t} ; \theta_{E}\right)\right)}^{\eta_{i t}\left(Z_{i t} ; \theta\right)}+\varepsilon_{i 1 t} \\
& u_{i 2 t}^{N}=\tilde{u}_{i 2 t}-\left(\eta_{i t}^{D}\left(Z_{i t} ; \theta_{D}\right)+\eta_{i t}^{E}\left(Z_{i t} ; \theta_{E}\right)\right)+\varepsilon_{i 2 t},
\end{aligned}
$$

which means that, when comparing utilities derived from each option, both costs cancel out. As this is also the case when there are $J$ PFAs in the choice set, the probability that 
person $i$ chooses alternative $j$ is given by

$$
\mathbb{P}_{i j t}^{N}=\frac{\exp \left(\tilde{u}_{i j t}\right)}{\sum_{l=1}^{J} \exp \left(\tilde{u}_{i l t}\right)} .
$$

Consider now the case of a returning enrollee who is currently enrolled in PFA 1. Her indirect utility derived from choosing either 1 or 2 is

$$
\begin{aligned}
& u_{i 1 t}^{R}=\tilde{u}_{i 1 t}-\eta_{i t}^{E}\left(Z_{i t} ; \theta_{E}\right)+\varepsilon_{i 1 t} \\
& u_{i 2 t}^{R}=\tilde{u}_{i 2 t}-\eta_{i t}^{D}\left(Z_{i t} ; \theta_{D}\right)-\eta_{i t}^{E}\left(Z_{i t} ; \theta_{E}\right)+\varepsilon_{i 1 t} .
\end{aligned}
$$

This means that, when comparing utilities, only the enrollment cost will cancel out and the decision cost will still be faced in case she switches to PFA 2. For this reason, the probability that she will choose PFA $j$ when there are $J$ PFAs in the market is

$$
\mathbb{P}_{i j t}^{R}=\frac{\exp \left(\tilde{u}_{i j t}\right)}{\sum_{l=1}^{J} \exp \left(\tilde{u}_{i l t}-\eta_{i t}^{D} \mathbb{1}\left[d_{i t-1} \neq l\right]\right)} .
$$

Finally, consider the case of an existing enrollee who is also enrolled in PFA 1. In this simple example this implies that her indirect utility function is given by

$$
\begin{aligned}
& u_{i 1 t}^{E}=\tilde{u}_{i 1 t}+\varepsilon_{i 1 t} \\
& u_{i 2 t}^{E}=\tilde{u}_{i 2 t}-\eta_{i t}^{D}\left(Z_{i t} ; \theta_{D}\right)-\eta_{i t}^{E}\left(Z_{i t} ; \theta_{E}\right)+\varepsilon_{i 2 t} .
\end{aligned}
$$

In this case, none of the switching costs will cancel out when comparing alternatives. For this reason, when there are $J$ PFAs in the market, the probability that an existing enrollee will choose alternative $j$ is given by

$$
\mathbb{P}_{i j t}^{E}=\frac{\exp \left(\tilde{u}_{i j t}\right)}{\sum_{l=1}^{J} \exp \left(\tilde{u}_{i l t}-\left(\eta_{i t}^{E}+\eta_{i t}^{D}\right) \mathbb{1}\left[d_{i t-1} \neq l\right]\right)} .
$$

Following the literature on discrete choice models, I allow for observed and unobserved heterogeneity in switching costs and taste coefficients. I assume that heterogeneity in these coefficients is normally distributed, with the mean and variance of each distribution to be estimated. In particular, each component of switching costs is a linear function of observed and unobserved demographics, $Z_{i t}$ and $\nu_{i}$ :

$$
\eta_{i t}^{h}\left(Z_{i t}, \nu_{i}^{h} ; \theta_{h}, \sigma_{h}\right)=\eta_{0}^{h}+\eta_{h} Z_{i t}+\sigma_{h} \nu_{i}^{h}
$$


where $h=\{$ decision, enrollment $\}$ and $\nu_{i}^{h} \sim N(0,1)$.

In the case of taste coefficients $\alpha$ and $\beta$ a similar specification is assumed. ${ }^{8}$ In particular

$$
\begin{aligned}
& \alpha_{i t}\left(D_{i t}^{\alpha}, \omega_{i}^{\alpha} ; \bar{\alpha}, \sigma_{\alpha}\right)=\alpha_{0}+\bar{\alpha} D_{i t}^{\alpha}+\sigma_{\alpha} \omega_{i}^{\alpha}, \\
& \beta_{i t}\left(D_{i t}^{\beta}, \omega_{i}^{\beta} ; \bar{\beta}, \sigma_{\beta}\right)=\beta_{0}+\bar{\beta} D_{i t}^{\beta}+\sigma_{\beta} \omega_{i}^{\beta}, \\
& \omega_{i}^{k} \sim N(0,1) \text { for } k=\{\alpha, \beta\} .
\end{aligned}
$$

Because of the distributional assumption about $\varepsilon$, the model only identifies differences in utility among options. In addition, because of the absence of an outside option, normalization is required. I define all alternative specific variables relative to PFA "Cuprum," which was always present, and normalize the unobserved characteristics of Cuprum to zero (i.e., $\left.\xi_{\text {Cuprum }}=0\right)$.

To account for unobserved heterogeneity $(\nu$ and $\omega)$, the demand model is estimated by Simulated Maximum Likelihood. In particular, I draw individuals for each random coefficient and component of switching costs. Then, for each simulated individual, the probability that she will choose alternative $j$ is obtained by integrating over the logit error given the random draws. This probability, denoting draws by $s$, corresponds to $\mathbb{P}_{i s j t}\left(d_{i t-1}, \mathbf{X}_{t}, Z_{i t}, \xi ; \alpha_{i s t}, \beta_{i s t}, \eta_{i s t}\right)=\int \mathbb{1}\left(u_{i s j t} \geq u_{i s l t}, \forall l \neq j \mid d_{i t-1}, \mathbf{X}_{t}, Z_{i t}, \xi ; \alpha_{i s t}, \beta_{i s t}, \eta_{i s t}\right) d F_{\varepsilon}$, where to save notation I have defined $\mathbf{X}_{j t}$ to include not only information on returns but also prices.

The probability that person $i$ will choose alternative $j$ is computed integrating over her simulated draws. In practice this is done by computing the mean over the simulated probabilities (Monte Carlo integration).

The Simulated Maximum Likelihood estimator is given by

$$
\hat{\theta}_{S M L}=\underset{\theta \in \Theta}{\arg \max } \sum_{i} \sum_{t} \sum_{j} \log \left(\mathbb{P}_{i j t}(\theta)\right) \mathbb{1}\left[d_{i t}=j\right],
$$

where $\mathbb{P}_{i j t}$ corresponds to the probability that enrollee $i$ chooses pension fund $j$ in period $t$, integrated over all unobservables.

\footnotetext{
${ }^{8} \mathrm{I}$ have also estimated the model assuming that $\omega^{\alpha}$ and $\omega^{\beta}$ are log-normally distributed. As the estimated parameters of such specification closely resemble those of the main specification, I do not report them in the paper. They are, however, available for the interested reader.
} 


\section{Choice Model Results}

\subsection{Parameter estimates}

Table 8 presents the estimated parameters of the choice model. The columns differ in i) the way in which past performance is measured; ii) whether past decisions are accounted for; and iii) whether the model is estimated with all the data or just initial choices. Column 1 measures performance using realized returns but does not consider past decisions, while column 2 includes past decisions in the estimation. Column 3 replicates column 1 using the absolute ranking of returns as the measure of past performance, while column 4 replicates column 2 using the absolute ranking of returns. Column 5 uses the relative ranking of realized returns, which is the absolute ranking divided by the number of PFAs in the market. For reasons that will be clarified in the following paragraphs, I also include a specification that only considers initial choices in column six. Finally, all specifications include PFA fixed effects to control for unobserved PFA characteristics.

There are several points to be noted. First, failure to consider past decisions has an important effect on the magnitude of the income coefficient. In particular, the estimated mean of the income coefficient is less than half of that estimated when considering past decisions. The intuition behind this result is simple. If there is significant inertia that is unaccounted for, the model rationalizes choices by reporting price insensitive enrollees. The magnitude of the income coefficient increases significantly once past decisions are considered.

Second, across specifications the estimated mean of the distribution of decision costs (the constant) is three times larger than the estimated mean of the distribution of enrollment costs, which explains why people rarely switch PFAs. This result is consistent with the findings of section 3, where it was reported that returning enrollees have lower switching costs than existing enrollees but are not free of them. In particular, switching costs of returning enrollees are, on average, 20-30\% lower than those of existing enrollees, which explains their higher switching rate.

Before exploring how inertia is related to observables, it is interesting to know how switching costs are distributed across the population. The distribution of switching costs, considering all demographic variables and integrating over the random draws, is presented in 
figure 8. The mean of the distribution of the decision cost is 3.96 with a standard deviation of 0.37 . For the case of the enrollment cost, the mean is 1.69 and the standard deviation is 0.27. Note that both the mean and standard deviation of the enrollment cost are lower than those of the decision cost. However, the coefficient of variation of the enrollment cost is $67 \%$ higher than that of the decision cost, which suggests that there is substantial heterogeneity in both.

I now turn to analyze how inertia is related to different observables. Across specifications we can see that both decision and enrollment costs increase with age and income, while gender is never significant. In addition, both switching costs increased significantly following new regulation introduced at the end of 1997, that was meant to make it difficult for sales people to induce uninformed switching from their competitors.

People who have a voluntary savings account have lower decision costs but slightly higher enrollment costs. To understand this result it is helpful to compare two individuals who differ only in that one has a voluntary savings account and the other does not. If both of them are returning enrollees this means that the one with the savings account has $10 \%$ lower decision costs. If both are existing enrollees, however, the difference in switching costs reduces to $3.7 \%$. In this sense, I use that some people have a voluntary savings account as to proxy for how much they might care about their investment problem. Finally, none of estimates of the standard deviations are significant. This suggests that the heterogeneity in switching costs is largely explained by the included demographic variables.

Figure 9 reports the distribution of switching costs for different values of observed demographics. The upper left panel plots the distribution of each switching cost for five age groups. It shows that both switching costs increase with age, that there is significant heterogeneity within each age group, and that the increment in switching costs seems to be monotonic.

The upper right panel shows the distribution of switching costs by gender. Although there is important dispersion within a gender, there is little difference when comparing women and men.

The lower left panel shows the distribution of switching costs for five different income groups and reveals that switching costs decrease smoothly with income. Intuitively, income 
plays two roles in a model with switching costs. On the one hand, high-income people have a higher alternative cost of time. On the other hand, if high-income people are also more educated and are more qualified to process the relevant information, then the decision process is less costly than for lower-income people. The results presented here suggest that the second effect dominates the first in the setting studied in this paper.

Finally, the lower right panel serves to visualize the effect of having a savings account on the decision cost. It also shows that the distribution of the enrollment cost is not affected by having a voluntary savings account.

I will now discuss the rest of estimated coefficients. The lower panel of table 8 reports the estimated taste coefficients. The marginal utility of income, $\alpha_{i t}$, has a positive and significant mean and important heterogeneity captured in the estimated standard deviation $\sigma_{\alpha}$. Older people have a lower marginal utility of income and the same is true for men. Figure 10(a) reports the frequency distribution of the marginal utility of income. The figure shows that the estimated parameter is positive for most people, though a non trivial fraction of people are either price insensitive or have a negative marginal utility of income. There are two reasons explain this. First, as people get closer to retirement they value past performance more than they did in the past and this is associated with a lower value for current income. In particular, the effect of performance on the balance of someone close to retirement is significantly more important than for a young individual, for whom the compounding of returns over time is more significant. Second, the taste coefficients are linear in age. As people get older the effect of age is more important, particularly because most of the sample is composed of young people. Finally, note that this result does not depend on the assumed distribution of the random draws. I also estimated the model assuming log-normal draws and, though the distribution shifts to the right, there is still a fraction of enrollees who show negative marginal utility of income because of the effect of age.

In order to understand what is generating the distribution of the marginal utility of income, I include two additional figures. First, figure 11(a) reports the distribution of $\alpha_{i t}$ for the three groups in the sample: new, existing, and returning enrollees. The figure shows that while new enrollees value income significantly more, the distribution for existing and 
returning enrollees is almost identical, though the two-sample Kolmogorov-Smirnov test rejected such hypothesis. This suggests that people are more price sensitive when making their initial choice than they are later on. This is also shown in figure 11(b), which reports reports the distribution of the income coefficient by age groups and shows that the whole distribution shifts to the left as people get older. This could happen because people may put their attention on past performance as they get closer to retirement and less concerned about fees and current income. Finally, though not reported here, conditional on the balance of the account, price sensitive increases with income, while conditional on income, price sensitivity decreases with the balance as people care more about past performance.

The coefficient for past performance is analyzed by focusing on the absolute ranking of returns, though the results are qualitatively similar when looking at the other measures. While the estimated mean is negative, the distribution of $\beta_{i t}$ shows that this parameter is concentrated on zero (figure 10(b) . This suggests that, contrary to the findings of other papers, people in the sample do not put much weight on past performance when making their decisions. In order to understand the interaction between this variable and fees, and gain insight into what may cause the difference between this finding and those reported elsewhere, I also present the distribution of the taste coefficient of past performance for each type of enrollee and age group. Figure 12(a) shows that existing and returning enrollees are more concerned about past performance than new enrollees. Figure 12(b) shows that, older enrollees care more about past performance than younger enrollees, which is different from their respective concern about fees. ${ }^{9}$ This is consistent with people closer to retirement focusing their attention on performance rather than fees, while younger enrollees do exactly the opposite. Because my data consists mostly of young people ( $80 \%$ of observations are generated by people younger than 35 years old), it is not surprising that past performance does not seem to be a determinant of choices. Thus, given what is reported in figure 12(b), one would likely expect a higher coefficient on past performance if the data included more people who are close to retirement. Note, however, that is still true that even for older people the coefficient is not far from zero.

Finally, in the previous section it was argued that measuring switching costs as if they

\footnotetext{
${ }^{9}$ The right tail of the distributions is not plotted.
} 
were tangible costs should not have an important effect on the estimated parameters because preferences are identified from initial choices. This is precisely what is shown in the last column of table 8 , though people appear to be more price sensitive in their initial choice, which was also shown in figure 11(a).

\subsection{Model fit}

In table 9 I report actual and predicted average choice probabilities (market shares) for the five biggest PFAs, for three different samples. The first three columns report choice probabilities according to the estimated parameters of the whole sample. The table shows that for the biggest PFAs fit is quite good. The fit is not so good for smaller PFAs, though they represent less than $7 \%$ of the market. This also shows the importance of incorporate alternative specific fixed effects, which help rationalizing observed market shares.

The next set of three columns use the same estimates but report choice probabilities for initial choices only. They show that, though fit is still good, it is not as good as the fit obtained when the whole sample is considered. This is a consequence of some PFAs having zero market share among initial choices, while the model predicts strictly positive probabilities for all of them. Finally, the last three columns report fit when estimation is done with only initial choices. These columns sow that the model does a very good job fitting the data. In this case, low probabilities for PFAs with zero market share are rationalized with very low values of $\xi$.

Overall, these results show that all estimates are robust to changes in the way in which past performance is measured. Furthermore, though not reported here, the key parameters of the specification of switching costs do not change significantly with alternative specifications such as not including PFA fixed effects (though the marginal utility of income changes significantly), using log-normal draws, and specifying an alternative model such as the one described in appendix A. Finally, I have also shown that when considering PFAs with large market shares, the model explains the data well. Now I turn to study how the different sources of inertia affect the way in which PFAs compete, and how policy targeted at reducing such inertia affects equilibrium outcomes. 


\section{Dynamic Price Competition and Policy Intervention}

In this section, I study whether distinguishing between coexisting switching costs is important for policy. To do so, I embed the static choice model in a dynamic pricing game. In this game, at the beginning of each period firms choose fees taking past enrollment as given. I apply this game to a variety of settings that correspond to different policies that target either a particular switching cost or guarantee that new enrollees are locked-in with the cheapest pension fund in the market. In addition, I also study how unexpected entry of a new pension fund affects competition.

\subsection{A Dynamic Pricing Game with Locked-In Consumers}

Assume that there are two pension funds, $j$ and $k$, and that consumers are currently enrolled as described by an enrollment matrix $E_{t}$. For simplicity, assume that $E_{t}$ is a matrix of zeros and ones, ones representing an enrollee who is currently enrolled with pension fund $j$. In each period $t$, the following game takes place:

1. Given the enrollment matrix $E_{t}$ and the history of past fees and returns that $E_{t}$ summarizes, funds compete by choosing fees $p_{j t}$ and $p_{k t}$ such that

$$
p_{j t}^{*} \in \underset{p \in P}{\arg \max } \pi_{j t}\left(\mathbf{p}, E_{t}\right)+\delta \mathbb{E}\left[V_{j, t+1}\left(\mathbf{p}, E_{t+1}\right)\right],
$$

where

$$
\pi_{j t}=p_{j t} \sum_{i=1}^{N} \int y_{i t} \mathbb{1}\left(u_{i j t} \geq u_{i k t} \mid E_{t}, p_{j t}, p_{k t}\right) d F_{\varepsilon},
$$

corresponds to fund's $j$ expected profits, which are computed given $E_{t}$ and a particular pair of fees, $N$ corresponds to the number of enrollees in the market, and $V_{j, t}$ corresponds to the discounted value of future payoffs starting in period $t$. Expected profits are computed over the probability that each enrollee may choose fund $j$, which

is a function of past enrollment, fees, past returns, and the idiosyncratic shock $\varepsilon_{i j t}{ }^{10}$

\footnotetext{
${ }^{10}$ Because, in practice, pension funds observe all the demographic information included in the specification of switching costs and random coefficients, I assume that these parameters are known to the pension funds. The alternative is to integrate over $\nu$ and $\omega$, which limits significantly the number of consumers I can simulate and increases significantly the time required to solve the game. This means that the only information pension funds do not know is the realization of $\varepsilon$.
} 
2. Consumer $i$ 's information set is $\Omega_{i t}=\left\{d_{i t-1}, p_{j t}, p_{k t}, r_{j t}, r_{k t}, y_{i t}, \eta_{i t}^{D}, \eta_{i t}^{E}, \alpha_{i t}, \beta_{i t}, \varepsilon_{i j t}, \varepsilon_{i k t}\right\}$, which consists on the current enrollment $\left(d_{i t-1}\right)$, fees, past returns, income, switching costs, random coefficients, and their shock $\varepsilon$. Given $\Omega_{i t}$, consumer $i$ chooses fund $j$ if $u_{i j t}\left(\Omega_{i t}\right) \geq u_{i k t}\left(\Omega_{i t}\right)$.

3. Given all enrollees' decisions, the enrollment matrix is updated to $E_{t+1}$ and static profits are realized.

The specification of the game requires further discussion about two assumptions. First, this specification means that $E_{t}$ is not only an enrollment matrix, but also the only state variable of the game. Indeed, because the distributions of switching costs, $\alpha$, and $\beta$ are continuous, any combinations of fees and returns results in a unique enrollment matrix. Therefore, every enrollment matrix summarizes a unique history of fees and returns, which makes $E_{t}$ the only state variable in this game. Second, as with the demand model, I assume that consumers are myopic in the sense that they make decisions based on current information (only $\Omega_{i t}$ is relevant and they do not consider expectations over future realization of random variables), and that they do not anticipate suffering from switching costs in the future. If they did, and this was anticipated by firms, then competition 'for' the market would compensate for lack of competition 'in' the market. Because consumers do not consider that they will be locked-in in future periods, firms have less incentives to compete fiercely.

To make the problem tractable, and to focus the analysis on the role of the different switching costs, I make three simplifications. First, during the period considered in this paper, the industry had between 7 and 22 firms, who used two-dimensional pricing strategies in which both dimensions are continuous. Simulating firm behavior in this context is far beyond what is currently possible without making more assumptions about the state variables. Instead, I focus on a duopoly market. For this reason, I analyze the effect of various policies by studying how fees change rather than the level of fees. In addition, to isolate the effect of switching costs on equilibrium fees, I assume symmetry across firms. ${ }^{11}$

\footnotetext{
${ }^{11}$ In the case of a duopoly this means that I assume that both pension funds offer the same returns and that there is no differentiation through $\xi$. I proceed in this way because only differences in fund-specific variables matter, not the level, and when considering the two largest PFAs in the market, the difference
} 
This means that consumers' decisions depend on the history of prices, enrollment, and the realization of the idiosyncratic shock $\varepsilon$.

The second simplification is that I assume funds charge only the percentage fee. Though this implies that part of the effect of inertia is lost (i.e., excess payments because of changes income), it is of little consequence for funds because, in practice, the fixed fee is a small fraction of the fees paid by enrollees. ${ }^{12}$ I proceed in this way because including the fixed fee increases the state space limiting the degree of consumer heterogeneity that can be considered in the simulations. Finally, note that this simplification would be incorrect if people had different sensitivity to the various types of fees. Exploring this is work in progress and I come back to this in Section 7 .

The third simplification is related to the way in which the game is specified. The literature on games with switching costs has evolved in two ways. Some papers have used two period models in an attempt to capture the investing-then-harvesting effect allowing for a rich demand system, while others have used infinite horizon models in which this trade-off is present in every period, but require simplifying the demand model. The standard result for those who have used two-period models is that prices are low in the first period and high in the second one. While those who use infinite horizon models are able to deal with this mechanic result, they must limit significantly the degree of consumer heterogeneity that they can introduce in simulations (see Dubé, Hitsch and Rossi, 2009). In addition, the game analyzed in this paper has a major difference with respect to most dynamic games analyzed in the literature. Indeed, because of the presence of new and returning enrollees, this game is not stationary. In other words, because in each period there is random entry between their estimated fixed effects is statistically not different from zero. In addition, as shown in figure 3. there is little dispersion on returns, so assuming that both firms offer the same returns eliminates an additional state variable with little cost. Note, however, that because of $\varepsilon$, funds are still differentiated products.

${ }^{12}$ In practice, the fixed fee represents, on average, $8.8 \%$ of total payments, with the median being $6.5 \%$. Furthermore, the financial records of the PFAs show that revenues generated by the percentage fee are much higher than those generated by the fixed fee. For example, in January of 2000, for seven of the eight PFAs in the market the percentage fee corresponded to between 93 and $100 \%$ of revenues generated by mandatory contributions. The exception was PFA Planvital in which case the percentage fee generated $81 \%$ of such revenues. 
and exit of enrollees, the game is not stationary and cannot be modeled as a stationary infinite horizon game. For these reasons, I take an intermediate step to keep consumer heterogeneity and allow for entry and exit of enrollees, while at the same time being able to compute equilibrium fees in a context of significant inertia. I simulate a three period game with full demand heterogeneity as estimated in section 5. Section 6.3 discusses the details of application and studies the impact on competition and welfare of policies that affect $\eta_{i t}^{D}$ and $\eta_{i t}^{E}$, or that directly assign new enrollees to the cheapest fund in the market.

\subsection{Equilibrium and Specification}

Because in each period pension funds compete simultaneously, taking as given the history of prices and enrollment, the equilibrium concept that I use is the subgame perfect Nash equilibrium. In this game, a subgame perfect Nash equilibrium is a sequence of fees $\boldsymbol{p}_{t}^{*}$ from period $t$ onwards such that for each fund $z$

$$
V_{z t}\left(E_{t}\left(\left\{p_{z l}^{*}\right\}_{l=0}^{t-1},\left\{p_{-z l}^{*}\right\}_{l=0}^{t-1}\right), \boldsymbol{p}_{z t}^{*}, \boldsymbol{p}_{-z t}^{*}\right) \geq V_{z t}\left(E_{t}\left(\left\{p_{z l}^{*}\right\}_{l=0}^{t-1},\left\{p_{-z l}^{*}\right\}_{l=0}^{t-1}\right), \boldsymbol{p}_{z t}, \boldsymbol{p}_{-z t}^{*}\right) \quad \forall \boldsymbol{p}_{z t}, t .
$$

Given the assumptions of the game, and the definition of equilibrium, I solve the problem by backward induction starting from the third period. In the third period, firms maximize their expected profits as in a static game. I solve fund's $j$ problem for each possible fee that fund $k$ may charge, and proceed in the same way for fund $k$ :

$$
p_{j 3}^{*}\left(p_{k 3}\right)=\underset{p_{j 3} \in P}{\arg \max } \quad p_{j 3} \sum_{i=1}^{N} \int y_{i 3} \mathbb{1}\left(u_{i j 3} \geq u_{i k 3} \mid E_{3}, p_{j 3}, p_{k 3}\right) d F_{\varepsilon} .
$$

To solve this problem it is necessary to discretize the state space. I do so by setting an upper $(40 \%)$ and lower $(-10 \%)$ limit to the fees that PFAs can charge, and discretizing the interval by values of $0.5 \%$. Both limits are far from any fee that PFAs have charged since the creation of the system, which guarantees that they do not bind.

Because of the discretization of the state space, that the game has finite horizon, and that $\pi$ is concave in $p$, each firm has an optimal fee for a given fee of its rival. Hence, I proceed by intersecting the best response functions of both firms $p_{j 3}^{*}\left(p_{k 3}\right)$ and $p_{k 3}^{*}\left(p_{j 3}\right)$. Once a pair of equilibrium fees is found, expected profits are computed. 
Once the equilibrium fees and revenues of the third stage are computed for all possible combinations of first and second period price differences (there are 40,401 possible combinations of such differences), I turn to solve the second stage. In the second stage, for any first-period price difference (there are 201 of these), each PFA chooses its optimal fee, for all possible prices that its rival may choose. This is, firm $j$ chooses $p_{j 2}$ such that

$$
p_{j 2}^{*}\left(p_{k 2}\right)=\underset{p_{j 2} \in P}{\arg \max } p_{j 2} \sum_{i=1}^{N}\left(\int y_{i 2} \mathbb{1}\left(u_{i j 2} \geq u_{i k 2} \mid E_{2}, p_{j 2}, p_{k 2}\right) d F_{\varepsilon}\right)+\beta \pi_{j 3}\left(p_{j 2}, p_{k 2}\right),
$$

where $\pi_{j 3}\left(p_{j 2}, p_{k 3}\right)$ corresponds to period three expected profits given the pair of fees $p_{j 2}$ and $p_{k 2}$. Fund $k$ chooses its fee in the same way. As before, I intersect the best responses $p_{j 2}^{*}\left(p_{k 2}\right)$ and $p_{k 2}^{*}\left(p_{j 2}\right)$ to compute second-period equilibrium fees and expected profits.

Finally, I solve the first period problem for each PFA, knowing that for any price they might choose, both firms will play optimally in periods two and three. As before, this means that in the first period fund $j$ solves

$$
p_{j 1}^{*}\left(p_{k 1}\right)=\underset{p_{j 1} \in P}{\arg \max } p_{j 1} \sum_{i=1}^{N}\left(\int y_{i 1} \mathbb{1}\left(u_{i j 1} \geq u_{i k 1} \mid p_{j 1}, p_{k 1}\right) d F_{\varepsilon}\right)+\beta \pi_{j 2}\left(p_{j 1}, p_{k 1}\right),
$$

where the only difference with period two is that consumers have no initial enrollment. As before, fund $k$ solves its problem in the same way. Finally, I assume that the game is played once a year and discount future expected profits assuming a discount factor $\delta$ equal to 0.95 .

\subsection{Application}

To solve this three-period game it is necessary to simulate a population of enrollees, who must make decision in each period. I simulate consumers according to the estimated parameters reported in Section 5. Consumers enter period one without any switching costs and $\alpha$ distributed according to the distribution estimated in Section 5. In contrast, in periods two and three, enrollees' decisions are affected by several factors. First, I assume that in each of these two periods, ten percent of enrollees leave the market and are replaced by new consumers who do not suffer from switching costs. In addition, another ten percent of enrollees are randomly chosen to be returning enrollees. This means that in periods two and three, when this group of enrollees (which is different in each period) makes their decisions, only decision costs matters. 
To study how switching cost affect consumer behavior and competition, I simulate different policies, each of which target a different switching cost. For this reason, by studying the impact of one policy at the time, I am able to identify the impact of each switching cost on competition and welfare. To do so, I start by simulating a base case that replicates my data in the context of a duopoly. This means that in this base case enrollees have switching costs as those estimated in Section 5, I then turn to study policies that target the enrollment cost, the decision cost, and policies that assign new enrollees to the cheapest PFA in the market. I finish this section by studying how entry of a new PFA affects competition.

The base case. In the base case, enrollees have switching costs as those estimated in Section 5. The results of this simulation are reported in the first column of 10 , and show that equilibrium fees increase over time, a result that follows from the finite horizon of the game. In the first period firms charge $2 \%$, while in the second and third periods they charge $9.5 \%$ and $17.5 \%$. In addition, the equilibrium of the game is symmetric, which means that firms charge equal fees and have the same market share every period (though fees change over time). However, it is interesting to know how firms would behave when they have different market shares. Table 11 reports fees in the second period for selected price differences in the first period. In this setting, if for any reason firms charged asymmetric fees in the first period (or more generally, the initial condition is not symmetric), they would also charge different fees in the second period, and these fees would be a function of their first period market shares. The results reported in the table show that the larger the price difference in the first period, the larger the price difference in the second period. A large price difference in the first period forces the small firm to price aggressively in the second one, though the price difference in the second period is far smaller than that of the first period.

No switching costs. The second simulation, reported in the second row of table 10 considers the case in which enrollees have no inertia (switching costs are set equal to zero). This completely eliminates the role of switching costs and leaves competition as the only determinant of equilibrium fees.

Equilibrium fees are the same across periods and equal to $7 \%$ when there is no inertia. This tells three things. First, the competitive effect associated with having more firms in 
the market is significant, with fees in the data ranging between $2 \%$ and $4 \% .{ }^{13}$ Second, in the absence of switching costs, fees in the second period (that is my measure of equilibrium fees) are $30 \%$ lower than when these costs exist. Third, only the existence of $\varepsilon$, that introduce differentiation, stands in the way of fees being driven to zero. In this setting, by introducing differentiation, $\varepsilon$ introduces market power that allows firms to charge positive fees.

In terms of consumer welfare, which is measured as the change in the discounted sum of expected utility (that corresponds to the inclusive value), the reduction in switching costs and the associated reduction in fees, increases consumer welfare by $4.62 \%$ (see table 13). To compute total welfare it is necessary to consider that, because of the lower fees, PFAs perceive lower profits. This results in total welfare increasing by $1.75 \%$ relative to the base case.

Policy intervention I: Eliminating enrollment costs (e.g., online enrollment). Eliminating enrollment costs reduces second-period fees by $5.3 \%$ relative to the base case (see table 10). Over the three periods this is associated with a $0.61 \%$ increment in consumer welfare. This lower increase in consumer surplus is explained by two reasons. First, only existing enrollees benefit from this type of policy. Second, for most existing enrollees decision costs are large enough that even without enrollment costs, they would not switch PFAs. For these reasons, the effect of eliminating enrollment costs is small relative to that of eliminating decision costs (see next paragraph). Finally, once lower profits are accounted for, total welfare increases in $0.5 \%$.

\section{Policy intervention II: Eliminating decision costs (e.g., delegated manage-} ment and personalized information). Eliminating decision costs affect both, returning and existing enrollees, and in both cases the effect, according to the results presented in section 5, should be significant. In terms of prices, the fourth row of table 10 shows that fees in periods one and two are lower than in the case in which there is no inertia, but in the first period these are higher than in the base case. On the other hand, fees in the third period are higher than when there is no inertia, but lower than in the base case. This shows

\footnotetext{
${ }^{13}$ There is a second reason that explains the difference in the level of fees. I have assumed that there is no outside option, which is correct for anybody who is employed in the formal sector. However, it is known that there are people in the margin willing to work in the informal sector in order to avoid paying fees and saving for retirement. In this paper I abstract from this situation and assume no outside option.
} 
that, because existing enrollees will suffer from enrollment costs in periods two and three, PFAs are willing to compete for them in the first period (and for any new or returning enrollee in periods two and three), lowering prices relative to the case with no inertia. The objective is to locked them in for the next periods. This result, that mimics that reported by Dubé, Hitsch and Rossi (2009) in the context of consumption goods, shows that identifying coexisting switching costs is critical for the effectiveness of policy. Indeed, this type of policy increases consumer surplus by $4.62 \%$ and total welfare by $1.68 \%$, which is slightly lower than that obtained when both sources of switching costs are eliminated.

As pointed out in the previous paragraph, this is not the first paper to show that switching costs can increase competition, and consumer welfare. Indeed, Dubé, Hitsch and Rossi (2009), Cabral (2013), and Arie and Grieco (2012), show that even in the presence of a single switching cost, when this cost is low, it can increase competition. This is, however, the first paper to show that this result can be obtained by targeting policy to a specific source of switching costs. This result depends on two things, the relative magnitude of each switching cost and the fraction of the population that is affected by each of the. To understand this, it is a good idea to explore the intuition of the result in the context of a single switching cost. Dubé, Hitsch and Rossi (2009) explain their result as a consequence of imperfect lock-in. In this setting, either investing or harvesting can dominate. Then, when switching costs are low, firms intensify competition to induce switching away from their competitors, which is anticipated by their rivals, who also decrease prices. This effect is not present when switching costs are high because the initial decrease in prices would need to be large enough to induce switching, sacrificing revenues from loyal consumers. Moreover, the effect is also not present when firms are myopic and the incentive to invest disappears. In this case, prices always increase in switching costs. They conclude, therefore, that low switching costs may induce tougher price competition. Cabral (2013) gives a similar explanation. He argues that, when switching costs are small, the impact of the harvesting effect on pricing depends on whether a firm is losing or gaining a customer. A firm who has a consumer benefits from increasing its price, though a firm who can gain a consumer decreases its price to induce switching. These two changes in price are of similar magnitudes and cancel each other. On the other hand, the impact of investing on prices is 
always negative, resulting in an overall decrease in prices. In the present paper, this effect is also present, but a new component is added. In particular, it is not only that switching costs decrease that results in prices below what they would be in the absence of switching costs, but also that each switching cost affects a different population. In particular, recall that enrollment costs can only affect decisions of existing enrollees, while decision costs affect choices of both returning and existing enrollees. Hence, it is not only that eliminating decision costs results in low switching costs, but also that it affects a larger group of the population. On the other hand, eliminating enrollment costs leaves returning consumers facing the same costs they faced before, and only benefits existing consumers. In addition, existing consumers still have large switching costs because of the magnitude of decision costs. Hence, in this application, both the magnitude of each switching cost as well as who is affected by each of them, are important in determining these results. In other words, if we observed that returning enrollees (almost) always switched, which would be rationalized as decision costs being (close) equal to zero and that enrollment costs generate (almost) all the inertia observed in the case of existing enrollees, then the policy recommendation would be the opposite, to target enrollment costs even though these only affect existing enrollees. ${ }^{14}$ Finally, note that because participation is mandatory, there is no distortion in the quantity being bought in this market. In general, though, switching costs distort quantities, which means that total welfare can either increase or decrease depending on the level of switching costs. In the application studied in this paper this is not possible because all changes in prices results from transfer between enrollees and pension funds. Hence, total welfare only changes because of the changes in switching costs. For this reason, total welfare increases more, mechanically, when all switching costs are eliminated than when only decision costs are eliminated. This result may not hold when switching costs also distort quantities.

Regulation (e.g., mandatory default option for new enrollees). In the fourth

\footnotetext{
${ }^{14}$ The level of equilibrium fees does depend on the initial condition in $t=1$, while the fact that fees can decrease below those charged in the absence of switching costs is robust. In particular, I simulated the game starting from an initial condition in which half of the enrollees are assigned to each PFA. In these simulations the path of fees is stable, with only a slight increase in the third, and final, period. However, it is still the case that when eliminating decision costs, fees decrease below those that are charged in the absence of switching costs.
} 
counterfactual exercise I simulate a policy that completely eliminates the decision process for new enrollees. This policy, based on a reform to the Chilean system done in 2009, allocates new enrollees to the PFA that charges the lowest price. Then, all new enrollees have to stay enrolled with the cheapest PFA for one period, and the PFA at the same time is required to charge the same price to old and new enrollees. If people are allocated to the PFA with the lowest price, and PFAs cannot price discriminate, then the regulator is guaranteeing that people would be enrolled with the cheapest alternative for at least one period.

This exercise introduces some complexity. In particular, there cannot be a symmetric equilibrium in pure strategies because if firms charged symmetric fees, both of them would be better off by lowering their fee and enrolling the mass of new consumers. For this reason, I solve for mixed a strategy equilibrium writing the problem as a linear quadratic problem as described by Mangasarian and Stone (1964). In particular, I first compute the payoff matrix of each fund, for each pair of fees that funds can choose. These correspond to pure-strategy payoffs if firms were to play pure strategies. Then, I exploit the fact that the game is a two-person non-zero sum game to rewrite the problem as proposed by Mangasarian and Stone (1964), and solve a linear quadratic problem in which the control variables are the probability distributions over the discretized set of pure strategies.

The results, reported in the last row of table 10, are interesting. First, in the last period expected fees (according to the equilibrium mixed strategies) are significantly lower than in the base case $(12 \%$ vs. $17.5 \%)$. Second, the expected price in periods one and two are lower than the equilibrium fees in the base case, and in the first period they are close to $0 \%$. This, in fact, shows the impact that assignment has on fees. In particular, this exercise shows that iteration of best responses (pure strategies) results in firms iterating between negative and positive prices close zero in the first stage. This discontinuity in best responses is introduced because in the first period every consumer is assigned to the firm with the lowest price. At the same time, that in the second and third period some consumers do switch in equilibrium (because of the $\varepsilon$ 's), makes funds to choose prices away from the minimum price in the grid.

Again, table 11 shows that fees in asymmetric states are higher than those that result 
when this regulation is not applied. As competition for new enrollees requires lowering the price significantly, the dominant firm focuses on its existing enrollees and gives up on competing for new enrollees. For this reason the resulting fees are significantly higher than in the case of no assignment. Finally, regulation is associated with a $2.6 \%$ increase in consumer surplus and $0.91 \%$ increase in total surplus.

Entry by a new PFA. Though the counterfactual exercises described above provide interesting results in terms of the impact of switching costs on equilibrium fees, they are lacking in at least one dimension. They approximate a market that had between seven and twenty two firms with just two. For computational reasons I cannot solve the game for three firms without significantly limiting the number of consumers that can be simulated. In order to deal with this I assume that two firms play the three-period game, where at the end of the third stage I introduce an unexpected fourth stage. In this fourth stage a new PFA is introduced in the market and enters with zero market share. This fourth stage is played as a static game and I focus on two cases. In the first case, enrollees (old and new) are free to choose PFA. This results in the incumbents charging $14 \%$ and the entrant charging $7.5 \%$. In the second case, new enrollees are assigned to the cheapest PFA. ${ }^{15}$ Once again, this implies that incumbents have no incentives to compete for new enrollees, which at the same time lowers the incentives for the entrant to compete fiercely. The resulting expected equilibrium fees are $14.5 \%$ for the incumbents and $9 \%$ for the entrants. I do not compute changes in welfare because, under the logit assumption, adding an alternative increases welfare mechanically.

Overall, in this section I have shown that eliminating decision costs can increase consumer welfare beyond the increase that results from eliminating both sources of switching costs. This result shows that distinguishing between coexisting switching cost may be critical for the effectiveness of policy. In addition eliminating the decision process for new enrollees results in lower fees, even though the rest of the population still faces significant switching costs. However, regardless of whether new enrollees are assigned to the cheapest PFA or not, fees are significantly higher in asymmetric states than when there is no iner-

\footnotetext{
${ }^{15}$ In this case I use the software developed by McKelvey, McLennan and Turocy (2010) to solve for the mixed strategy equilibrium.
} 
tia. This happens because the dominant firm specializes in its existing base and does not compete for new enrollees. Thus, this means that the idea that switching costs result in higher equilibrium fees does not necessarily hold for asymmetric states. Finally, I showed that when a new PFA enters the market, it does so by specializing in new enrollees, and this entry results in lower equilibrium fees than in the case of a duopoly. However, regulation that assigns when new enrollees to the cheapest PFA, eliminates the incentives of a dominant firm to compete for new enrollees. This results in equilibrium fees that are higher than when such regulation is not implemented. Nonetheless, fees paid by enrollees that switch are lower with such policy than without it.

All these results suggest that, from the perspective of enrollees, there is an optimal level of switching costs, and that a planner may be interested in choosing this level of switching costs to maximize consumer welfare. This question, that I leave for future research, suggests that a way in which the planner may do this is by completely eliminating switching costs, but introducing a tax over switching, or, instead, identifying the optimal level of enrollment and decision costs. As argued above, this latter approach might be sensible to the fraction of enrollees that face each switching cost, which highlights the importance of distinguishing both the relative magnitude of coexisting switching costs and who is affected by them.

\section{Conclusions}

In many markets consumers suffer from switching costs which deter them from switching to alternative products. Because, in practice, multiple switching costs coexist, and the different costs may affect different people, it is difficult to design and implement policy that may reduce the impact of switching costs on consumer behavior and competition. In this context, this paper studies two questions. First, is it possible to identify and quantify coexisting switching costs? Second, is it important to distinguish coexisting switching costs? To answer these questions, I study the Chilean pension system, which institutional features allow me to identify two coexisting switching costs: the cost associated with analyzing financial information and choosing a pension fund, and the cost associated with the bureaucracy of switching pension funds. 
Using a structural choice model, I find that there is significant inertia in investment choices, most of which is associated with the cost faced when deciding whether to switch pension funds or not. The rest is associated with the bureaucratic enrollment process required to switch pension funds. I identify the relative magnitude of these costs by comparing decisions of different groups of enrollees, whose decisions are affected by the different sources of switching costs. The results show that there is significant heterogeneity in switching costs across the population: switching costs increase with age, decrease with income, and are significantly lower for people who voluntarily save resources in addition to those specified by the defined contribution rate.

To study whether distinguishing coexisting switching is important for policy, I embed the choice model in a dynamic pricing game. I apply the game to a variety of settings, determined by different policies that eliminate the different switching costs that consumers face. I find that that eliminating decision costs increase consumer welfare eight times more than eliminating enrollment costs, and $8 \%$ more than eliminating both switching costs. These results follow from low switching costs resulting in lower equilibrium fees than when all switching costs are eliminated, which dominates the negative impact of consumers facing higher switching costs. This also shows that distinguishing coexisting switching costs might indeed be critical for the effectiveness of policy. Finally, I show that regulation that allocates new enrollees to the cheapest pension fund in the market is associated with $5.3 \%$ lower equilibrium prices, but higher fees when firms differ in market shares. The key determinant of these results is the trade-off introduced because pension funds are not allowed to price discriminate. This implies that they must balance the incentives to invest in new enrollees, with the incentives to extract surplus from their existing base. In asymmetric states the inability to price discriminate results in the dominant firm abandoning any hope of enrolling those who enter the market and concentrating on those that form its current base.

Three topics are left for future research. First, in this industry pension funds charge two-dimensional fees and are not allowed to price discriminate between enrollees. Because it is known that people may perceive each type of fee differently in such settings (see Abaluck and Gruber, 2011), understanding how different price-sensitivities interact with inertia and price discrimination is work in progress. Second, it is also interesting to un- 
derstand how the way in which pension funds choose their investment portfolios is affected by inertia and policy. In particular, the change in regulation that affected the enrollment practices of the industry in 1997 increased switching costs significantly. For this reason, studying how this change in regulation affected the way in pension funds chose their investment strategies is important. Finally, between 1994 and 1996 this industry saw a significant number of mergers that had little impact on enrollees' choices because of the existing switching costs. However, evaluating the impact of these mergers, and particularly of subsequent merges is, I believe, a fruitful area of future research.

\section{References}

Abaluck, Jason, and Jonathan Gruber. 2011. "Choice Inconsistencies Among the Elderly: Evidence from Plan Choice in the Medicare Part D Program." The American Economic Review, 101(4): 1180-1210.

Arie, Guy, and Paul L.E. Grieco. 2012. "Do Firms Compensate Switching Consumers?"

Beggs, Alan, and Paul Klemperer. 1992. "Multi-Period Competition with Switching Costs." Econometrica: Journal of the Econometric Society.

Bernstein, Solange, and Alejandro Micco. 2002. "Turnover and Regulation: The Chilean Pension Fund Industry." Banco Central de Chile Documento de Trabajo 180.

Bernstein, Solange, and Carolina Cabrita. 2006. "Los Determinantes de la Elección de AFP en Chile: Nueva Evidencia a Partir de Datos Individuales." Superintendencia de AFP Documento de Trabajo 19.

Bernstein, Solange, and José Luis Ruiz. 2004. "Sensibilidad de la Demanda con Consumidores Desinformados: El caso de las AFP en Chile." Superintendencia de AFP Documento de Trabajo 4.

Beshears, John, James J. Choi, David Laibson, and Brigitte C. Madrian. 2013. "Simplification and saving." Journal of Economic Behavior \& Organization, 95(0): 130145 . 
Beshears, John, James J. Choi, David Laibson, Brigitte C. Madrian, and Katherine L. Milkman. 2011. "The Effect of Providing Peer Information on Retirement Savings Decisions.” National Bureau of Economic Research Working Paper 17345.

Cabral, Luís. 2013. "Dynamic Pricing in Customer Markets with Switching Costs."

Carroll, Gabriel D., James J. Choi, David Laibson, Brigitte C. Madrian, and Andrew Metrick. 2009. "Optimal Defaults and Active Decisions." The Quarterly Journal of Economics, 124(4): 1639-1674.

Cerda, Rodrigo. 2005. "Movilidad en la Cartera de Cotizantes por AFP: La Importancia de ser Primero en Rentabilidad." Pontificia Universidad Católica de Chile Documento de Trabajo 309.

Chetty, Raj, John N. Friedman, Soren Leth-Petersen, Torben Nielsen, and Tore Olsen. 2012. "Active vs. Passive Decisions and Crowdout in Retirement Savings Accounts: Evidence from Denmark." National Bureau of Economic Research Working Paper 18565.

Choi, James J., David Laibson, and Brigitte C. Madrian. 2009. "Reducing the Complexity Costs of 401(k) Participation Through Quick Enrollment"." Developments in the Economics of Aging, , ed. David A. Wise, 57-82. University of Chicago Press.

Choi, James J., David Laibson, and Brigitte C. Madrian. 2010. "Why Does the Law of One Price Fail? An Experiment on Index Mutual Funds." Review of Financial Studies, 23(4): 1405-1432.

Choi, James J., David Laibson, and Brigitte C. Madrian. 2011. "100 Bills on the Sidewalk: Suboptimal Investment in 401(k) Plans." The Review of Economic Studies, 93(3): 748-763.

Crawford, George S., Nicola Tosini, and Keith Waehrer. 2011. "The Impact of 'Rollover' Contracts on Switching Costs in the UK Voice Market: Evidence from Disaggregate Customer Billing Data." SSRN Working Papers Series DP8693. 
Duarte, Fabian, and Justine Hastings. 2009. "Fettered Consumers and Sophisticated Firms: Evidence from Mexico's Privatized Social Security Market."

Dubé, Jean-Pierre, Günter J. Hitsch, and Peter E. Rossi. 2009. "Do Switching Costs Make Markets Less Competitive?" Journal of Marketing Research, 46(4): pp. 435445 .

Ericson, Keith M. Marzilli. 2012. "Consumer Inertia and Firm Pricing in the Medicare Part D Prescription Drug Insurance Exchange." National Bureau of Economic Research Working Paper 18359.

Farrell, Joseph, and Paul Klemperer. 2007. "Coordination and Lock-in: Competition with Switching Costs and Network Effects." Handbook of industrial organization, 3: 19672072 .

Ferreiro, Alejandro, ed. 2003. The Chilean Pension System. . Fourth ed., Superintendencia de Administradoras de Fondos de Pensiones.

Handel, Benjamin. 2013. "Adverse Selection and Inertia in Health Insurance Markets : When Nudging Hurts." The American Economic Review, Forthcoming.

Hastings, Justine. 2010. "Investor Decisions and the Financial Crisis in Mexico's Privatized Social Security Market."

Hastings, Justine, and Lydia Tejeda-Ashton. 2008. "Financial Literacy, Information, and Demand Elasticity: Survey and Experimental Evidence from Mexico."

Hastings, Justine, Olivia S. Mitchell, and Eric Chyn. 2010. "Fees, Framing, and Financial Literacy in the Choice of Pension Manager."

Hastings, Justine S., Ali Hortaçsu, and Chad Syverson. 2013. "Advertising and Competition in Privatized Social Security: The Case of Mexico." National Bureau of Economic Research Working Paper 18881.

Hortaçsu, Ali, Seyed Ali Madanizadeh, and Steve Puller. 2011. "Power to Choose: An Analysis of Consumer Behaviour in the Texas Retail Electricity Market." Working Paper. 
Klemperer, Paul. 1987a. "Markets with Consumer Switching Costs." The Quarterly Journal of Economics, 102(2): 375-394.

Klemperer, Paul. 1987b. "The Competitiveness of Markets with Switching Costs." The RAND Journal of Economics, 18(1): pp. 138-150.

Luco, Fernando. 2013. "Distinguishing Sources of Inertia in a Defined-Contribution Pension-System."

Madrian, Brigitte C., and Dennis F. Shea. 2001. "The Power of Suggestion: Inertia in 401(k) Participation and Savings Behavior." The Quarterly Journal of Economics, 116(4): pp. 1149-1187.

Mangasarian, Olvi L., and H Stone. 1964. "Two-Person Nonzero-Sum Games and Quadratic Programming." Journal of Mathematical Analysis and Applications, 9(3): 348355.

Marinovic, Iván, and Salvador Valdés. 2005. "La Demanda de las AFP Chilenas: 1993-2002." Pontificia Universidad Católica de Chile.

McKelvey, Richard D., Andrew M. McLennan, and Theodore L. Turocy. 2010. "Gambit: Software Tools for Game Theory."

Miravete, Eugenio J., and Ignacio Palacios-Huerta. forthcoming. "Consumer Inertia, Choice Dependence and Learning from Experience in a Repeated Decision Problem." The Review of Economic Studies.

Thaler, Richard H, and Cass R Sunstein. 2008. Nudge: Improving decisions about health, wealth, and happiness. Yale University Press. 


\section{A Sequential model}

In this section, I explore a slightly different demand model in which enrollees act in stages. The main difference between this model and the one explored in the main text is the way in which switching costs are modeled. In this section, I assume that an enrollee first decides whether to 'think' about the decision problem, in which case she incurs in decision costs. If she decides not to face the decision problem, she does not incur in decision costs and remains enrolled in her current PFA. If she decides to face the decision problem, she has to decide which is the best alternative in the choice set and then decide whether to switch or not. If she decides to switch, she also pays enrollment costs.

In this model the probability that person $i$ will choose alternative $k$ in period $t$ is given by

$$
\begin{aligned}
\mathbb{P}_{i}(k) & =\mathbb{P}_{i}(k \mid \text { think }) \mathbb{P}_{i}(\text { think })+\mathbb{P}_{i}(k \mid \text { not think }) \mathbb{P}_{i}(\text { not think }) \\
& =\mathbb{P}_{i}(\text { think }) \mathbb{P}_{i}\left(k \in \underset{z \in J}{\arg \max } E\left[u_{i z t}\right] \mid \text { think }\right)+\underbrace{\mathbb{P}_{i}(k \mid \text { not think })}_{1 \text { if } d_{i t-1}=k, 0 \text { otherwise }} \mathbb{P}_{i} \text { (not think }) .
\end{aligned}
$$

To compute the different probabilities of this expression, it is necessary to know the status of each enrollee.

\section{A.1 New enrollee}

In the case of a new enrollee, the probability of choosing alternative $k$ is given by

$$
\mathbb{P}_{i}^{n}(k)=\frac{\exp \left(\tilde{u}_{i k t}\right)}{\sum_{l \in J} \exp \left(\tilde{u}_{i l t}\right)}
$$

where $\tilde{u}_{i l t}=\alpha_{i t}\left(y_{i t}-0.1 y_{i t}-f_{l t}-p_{l t} \min \left\{y_{i t}, \bar{y}_{t}\right\}\right)+X_{l t}^{\prime} \beta_{i t}+\xi_{l}$.

\section{A.2 Returning enrollee}

A returning enrollee faces a trade-off between thinking about the problem, knowing that after thinking and incurring in decision costs she will choose the alternative that gives her the highest utility, or not thinking and remain enrolled in her current PFA. If she decides not to think about the problem, the probability of choosing alternative $k$ is one if $k$ was chosen in the last active period and zero otherwise. If, on the other hand, she decides to incur in 
decision costs, she will choose the alternative that gives her the higher utility, no matter the enrollment costs. Hence, she must compare the expected utility derived from thinking with the expected utility of not thinking. Because of the assumption on the distribution of $\varepsilon$, the expected utility of thinking is given by the inclusive value associated with a particular choice set. This is,

$$
I V_{i t}^{r}=\ln \left(\sum_{z \in J} \exp \tilde{u}_{i z t}\right)
$$

On the other hand, the expected utility of not thinking when the enrollee is currently enrolled in PFA $j$ is given by

$$
E_{\varepsilon}\left[\tilde{u}_{i j t}+\varepsilon_{i j t}\right]=\tilde{u}_{i j t}+\gamma
$$

where $\gamma$ corresponds to Euler's constant.

Hence, the probability that person $i$ will think about choosing a PFA is given by,

$$
\begin{aligned}
\mathbb{P}_{i}^{r}(\text { think }) & =\mathbb{P}\left(I V_{i t}^{r}-\tilde{\eta}_{i t}^{M} \geq \tilde{u}_{i j t}+\gamma\right) \\
& =\mathbb{P}\left(I V_{i t}^{r}-\left(\eta_{i t}^{M}+\zeta_{i t}^{m}\right) \geq \tilde{u}_{i j t}+\gamma\right) \\
& =\Phi\left(I V_{i t}^{r}-\eta_{i t}^{M}-\tilde{u}_{i j t}-\gamma\right)
\end{aligned}
$$

where I have assumed that $\zeta_{i t}^{M}$ is distributed according to a standard normal distribution.

Conditional on thinking, the probability that an enrollee will choose alternative $k$ is then given by,

$$
\mathbb{P}_{i}^{r}(k \mid \text { think })=\frac{\exp \left(\tilde{u}_{i k t}-\eta_{i t}^{E} \mathbb{1}\left[d_{i t-1} \neq k\right]\right)}{\sum_{l \in J} \exp \left(\tilde{u}_{i l t}-\eta_{i t}^{E} \mathbb{1}\left[d_{i t-1} \neq l\right]\right)} .
$$

The probability that a returning enrollee chooses alternative $k$ is given by,

$\mathbb{P}_{i}^{r}(k)=\Phi\left(I V_{i t}^{r}-\eta_{i t}^{M}-\tilde{u}_{i j t}-\gamma\right) \frac{\exp \left(\tilde{u}_{i k t}-\eta_{i t}^{E} \mathbb{1}\left[d_{i t-1} \neq k\right]\right)}{\sum_{l \in J} \exp \left(\tilde{u}_{i l t}-\eta_{i t}^{E} \mathbb{1}\left[d_{i t-1} \neq l\right]\right)}+\left(1-\Phi\left(I V_{i t}^{r}-\eta_{i t}^{M}-\tilde{u}_{i j t}-\gamma\right)\right) \mathbb{1}\left[d_{i t-1}=k\right]$

\section{A.3 Existing enrollee}

In the case of the existing enrollee, the probability of choosing alternative $k$ is similar to that in the case of a returning enrollee, with one important difference. When computing the expected utility of thinking, the enrollee also considers the enrollment cost in the inclusive value. This is,

$$
I V_{i t}^{e}=\ln \left(\sum_{z \in J} \exp \tilde{u}_{i z t}-\eta_{i t}^{E} \mathbb{1}\left[d_{i t-1} \neq z\right]\right)
$$


Therefore, the probability that an existing enrollee will choose alternative $k$ is given by

$\mathbb{P}_{i}^{e}(k)=\Phi\left(I V_{i t}^{e}-\eta_{i t}^{M}-\tilde{u}_{i j t}-\gamma\right) \frac{\exp \left(\tilde{u}_{i k t}-\eta_{i t}^{E} \mathbb{1}\left[d_{i t-1} \neq k\right]\right)}{\sum_{l \in J} \exp \left(\tilde{u}_{i l t}-\eta_{i t}^{E} \mathbb{1}\left[d_{i t-1} \neq l\right]\right)}+\left(1-\Phi\left(I V_{i t}^{e}-\eta_{i t}^{M}-\tilde{u}_{i j t}-\gamma\right)\right) \mathbb{1}\left[d_{i t-1}=k\right]$

\section{A.4 Simulated Log Likelihood}

Given the expressions defined above, the probability that person $i$ chooses alternative $k$ is given by her contribution status. This is,

$$
\mathbb{P}_{i}(k)=\left(\mathbb{P}_{i}^{n}(k)\right)^{\mathbb{1}[\text { new }]}\left(\mathbb{P}_{i}^{r}(k)\right)^{\mathbb{1}[\text { returning }]}\left(\mathbb{P}_{i}^{e}(k)\right)^{\mathbb{1}[\text { enrolled }]} .
$$

The Simulated Log Likelihood is given by

$$
S L L(\theta)=\sum_{i, l, t} \log \left(\mathbb{P}_{i t}(l)\right) \mathbb{1}\left[d_{i t}=l\right]
$$

\section{A.5 Discussion and results}

This model resolves the main disadvantage of the model proposed in the main text, namely that it is possible that some people may decide to incur in decision costs and yet choose to remain enrolled with their current option. In this case, the model presented in the text would overestimate switching costs in an attempt to rationalize that some enrollees do not switch after going through the decision process. This is solved by the specification presented here. However, this specification introduces a major interpretation difficulty. In particular, in order to compute the expected utility of thinking about actively choosing a PFA (so, to compute the inclusive value), people must know which options are in the choice set, their prices, and past performance. The only thing they do not know is the realization of $\varepsilon$. In other words, before deciding whether to actively choose or not, they must have and process all the information that is costly to process. Hence, the interpretation of $\eta^{M}$ is no longer trivial. For this reason, I have chosen a simpler model that though overestimates the mean of each switching costs, but not how these costs vary with demographics, it does not suffer from this interpretation problem.

The estimated parameters of this model, for three different specifications, are presented in table 1, The results show three important observations. First, switching costs are lower 
than those reported in the main text. As explained above, this was expected because this model allows for people deciding to think and later choosing their current option. Second, it is still true that most of inertia is explained by the decision cost. Third, with the exception of the impact of regulation introduced in 1997, all parameters are similar, in sign and magnitude, to those reported in the main text, so the interactions are not affected by the overestimation of the mean. Finally, this model shows that regulation introduced in 1997 affected much more the enrollment cost (increasing it), than the decision cost. This result was what the regulator had aimed when it introduced this regulation, and this was not captured in the model presented in the main text. 
Table 1: Estimated parameters of the alternative choice model

\begin{tabular}{|c|c|c|c|c|}
\hline & & \multicolumn{3}{|c|}{ Past performance measured by } \\
\hline & & $\begin{array}{c}\text { Returns } \\
\text { (1) }\end{array}$ & $\begin{array}{c}\text { Absolute ranking of returns } \\
\text { (2) }\end{array}$ & $\begin{array}{c}\text { Relative ranking of returns } \\
\text { (3) }\end{array}$ \\
\hline \multirow[t]{14}{*}{ Decision cost } & Constant & 2.401 & 2.384 & 2.390 \\
\hline & & $(0.036)$ & $(0.036)$ & $(0.036)$ \\
\hline & Age & 0.009 & 0.009 & 0.009 \\
\hline & & $(0.001)$ & $(0.001)$ & $(0.001)$ \\
\hline & Gender & 0.0002 & 0.001 & 0.002 \\
\hline & & $(0.018)$ & $(0.018)$ & $(0.018)$ \\
\hline & Income & -0.002 & -0.002 & -0.002 \\
\hline & & $(0.0003)$ & $(0.0003)$ & $(0.0003)$ \\
\hline & Voluntary savings & -0.205 & -0.207 & -0.206 \\
\hline & & $(0.019)$ & $(0.020)$ & $(0.019)$ \\
\hline & Regulation & -0.012 & -0.015 & -0.018 \\
\hline & & $(0.019)$ & $(0.019)$ & $(0.019)$ \\
\hline & $\sigma^{D}$ & 0.016 & 0.014 & 0.014 \\
\hline & & $(0.016)$ & $(0.016)$ & $(0.016)$ \\
\hline \multirow[t]{14}{*}{ Enrollment cost } & Constant & 0.674 & 0.674 & 0.667 \\
\hline & & $(0.041)$ & $(0.041)$ & $(0.041)$ \\
\hline & Age & 0.003 & 0.003 & 0.003 \\
\hline & & $(0.001)$ & $(0.001)$ & $(0.001)$ \\
\hline & Gender & -0.031 & -0.032 & -0.031 \\
\hline & & $(0.021)$ & $(0.021)$ & $(0.021)$ \\
\hline & Income & 0.0004 & 0.0002 & 0.0001 \\
\hline & & $(0.0004)$ & $(0.0004)$ & $(0.0004)$ \\
\hline & Voluntary savings & 0.109 & 0.113 & 0.113 \\
\hline & & $(0.022)$ & $(0.022)$ & $(0.022)$ \\
\hline & Regulation & 0.115 & 0.143 & 0.161 \\
\hline & & $(0.022)$ & $(0.022)$ & $(0.022)$ \\
\hline & $\sigma^{E}$ & -0.005 & 0.005 & 0.004 \\
\hline & & $(0.019)$ & $(0.019)$ & $(0.019)$ \\
\hline \multirow[t]{8}{*}{ Marginal utility of income } & Constant & 3.316 & 3.256 & 3.363 \\
\hline & & $(0.236)$ & $(0.235)$ & $(0.235)$ \\
\hline & Age & -0.091 & -0.090 & -0.093 \\
\hline & & $(0.007)$ & $(0.007)$ & $(0.007)$ \\
\hline & Gender & -0.424 & -0.422 & -0.436 \\
\hline & & $(0.112)$ & $(0.112)$ & $(0.112)$ \\
\hline & $\sigma^{\alpha}$ & -0.091 & 0.083 & 0.080 \\
\hline & & $(0.089)$ & $(0.089)$ & $(0.089)$ \\
\hline \multirow[t]{10}{*}{ Marginal utility of returns } & Constant & -0.014 & -0.014 & 0.007 \\
\hline & & $(0.006)$ & $(0.004)$ & $(0.057)$ \\
\hline & Age & 0.001 & 0.001 & 0.010 \\
\hline & & $(0.0002)$ & $(0.0002)$ & $(0.002)$ \\
\hline & Gender & 0.003 & -0.001 & -0.005 \\
\hline & & $(0.003)$ & $(0.002)$ & $(0.028)$ \\
\hline & Income & $-9.11 \mathrm{E}-005$ & 0.000 & 0.002 \\
\hline & & $(4.40 \mathrm{E}-005)$ & $(3.32 \mathrm{E}-005)$ & $(0.0004)$ \\
\hline & $\sigma^{\beta}$ & 0.002 & 0.002 & 0.025 \\
\hline & & $(0.002)$ & $(0.002)$ & $(0.028)$ \\
\hline McFadden's Pseudo $R^{2}$ & & 0.87005 & 0.87027 & 0.87043 \\
\hline Number of observations & 350,660 & & & \\
\hline
\end{tabular}

Asymptotically robust standard errors in parentheses. PFA fixed effects included in all specifications. The dependent variable is an

indicator that is equal to one for the chosen PFA and zero for the rest. Estimation is via Simulated Maximum Likelihood. 


\section{B Alternative sources of switching costs}

This paper models two sources of switching costs: the cost associated with making a decision and the cost associated with the bureaucratic enrollment process. While enrollment costs are cleanly associated with a bureaucratic process, there is a risk that decision costs may be confounding the cost of making decisions with other sources of inertia, such as search costs. In this section I argue that, in the setting studied in this paper, these sources of inertia are likely to be of second order relative to the actual cost of making a decision.

There are several arguments that suggest that decision costs refer to the cost associated with making a decision that requires analyzing financial information, and not with alternative sources of inertia such as search costs. These arguments can be classified in two categories. The first category consists of arguments related to the type and frequency with which consumers receive information, without requiring them to search for it. Both the type and frequency of information suggest that decision costs refer to the cost of analyzing information rather than gathering it (search costs). The second category refers to what can be labeled as circumstantial evidence. Though this evidence is of a later period, it also suggests that what is costly is to analyze financial information. In the next paragraphs I describe each of these arguments.

The arguments classified in the first category refer to the type and frequency with which consumers receive information. In the Chilean pension system, enrollees receive information in several ways. The most common source of information is personalized statements that are sent out three times per year. These statements include information on the balance of the account, contributions, and fees paid. In addition, they also compare the fees that enrollees would pay for all PFAs in the market, as well as different measures of past performance. The information in these statements, though sent by each PFA to its enrollees, is elaborated by the supervisor. Also, mergers and changes in prices (positive and negative), are informed in addition to the statements that are sent out every four months. The large number of mergers and changes in prices, shown in figures 1(a), 2(a), and 2(b), suggests that enrollees received information frequently about all PFAs in the market. This means that inertia is likely caused by the difficulty of analyzing financial information rather than lack of information that would result from search costs. 
Two pieces of circumstantial evidence fall in the second category of arguments. First, following a major reform, in 2010 PFA Modelo entered the system. When entering, Modelo's fee was $18 \%$ lower than that charged by the cheapest PFA in the market (and $21 \%$ lower than the second cheapest), and in 2012, Modelo decreased its fee again, increasing the difference between its fee and that of the cheapest alternative to $41 \%$. However, until December 2012, only one of the alternative PFAs had lost enrollees, while all the rest had attracted enrollees. This is important because the reform guaranteed that Modelo would receive all new enrollees (as in the case of the regulation counterfactual of Section 6), who would not be allowed to switch PFAs for two years. Hence, the fact that the rest of the PFAs where able to increased their number of enrollees suggests that these came from the only PFA that lost enrollees (Provida) rather than from new enrollees. At the same time, the number of people enrolled in Modelo correspond mainly to people who are entering the system, and not people switching away from high-fee PFAs. Because the reform, the entry of Modelo, and the price differential were significantly advertised, neither search costs nor inattention seem to be a likely explanation for inertia.

Finally, to understand the second piece of circumstantial evidence, it is necessary to recall that since 2002 pension funds are allowed to offer up to five investment funds, for which they charge the same price. Hence, when deciding whether to switch funds, only risk preferences matter. In this setting, and after Modelo entered the system, a consulting company for created. This company gives advice to its customers related to in which fund to invest (not PFA). This firm advices its customers by sending them emails suggesting moving their savings from one fund to another, within a PFA. Since this firm was created, the number of changes of funds has been the highest since the system was formed, and forced the regulator to intervene because not all the changes were associated with enrollees obtaining higher returns. In this sense, this shows that is not that people do no receive information, but that they dislike making the decision. Once someone makes the decision for them, even if it charges a fee for doing so, people do switch.

Overall, these two pieces of circumstantial evidence, in addition to the information structure described above, suggest that what causes inertia is that people dislike making decisions, and not alternative explanations such as search costs. 


\section{Tables}

Table 2: Evolution of investment limits

\begin{tabular}{|c|c|c|c|c|}
\hline \multirow[t]{2}{*}{ Instrument } & \multicolumn{2}{|c|}{1989} & \multicolumn{2}{|c|}{1999} \\
\hline & Lower limit & Upper limit & Lower limit & Upper limit \\
\hline Government securities & \multicolumn{2}{|c|}{$50 \%$} & $35 \%$ & $50 \%$ \\
\hline Mortgage-backed securities & $40 \%$ & $100 \%$ & $35 \%$ & $50 \%$ \\
\hline $\begin{array}{l}\text { Time deposits, bonds, other } \\
\text { securities representing } \\
\text { loans and guaranteed by } \\
\text { financial institutions }\end{array}$ & $\begin{array}{l}40 \% \text { if at } \\
\text { least have a } \\
\text { term of } 1 \text { year } \\
30 \% \text { otherwise }\end{array}$ & $100 \%$ & $30 \%$ & $50 \%$ \\
\hline $\begin{array}{l}\text { Bonds of Public }+ \text { Private } \\
\text { companies }\end{array}$ & $30 \%$ & $100 \%$ & $30 \%$ & $50 \%$ \\
\hline Open de-concentrated plc shares ${ }^{a}$ & & - & $30 \%$ & $40 \%$ \\
\hline Real estate plc shares ${ }^{b}$ & $10 \%$ & $-\quad 30 \%$ & $10 \%$ & $20 \%$ \\
\hline Open concentrated plc shares ${ }^{a}$ & & $10 \%$ & & \\
\hline Commodities investment fund shares & Not aut & orized & $5 \%$ & $10 \%$ \\
\hline Real estate investment fund shares ${ }^{b}$ & Not aut & orized & $10 \%$ & $20 \%$ \\
\hline Company development investment fund shares & Not aut & orized & $2 \%$ & $5 \%$ \\
\hline Securitized loans investment fund shares & Not aut & orized & $5 \%$ & $10 \%$ \\
\hline International investment fund shares ${ }^{c}$ & Not aut & orized & $3 \%$ & $6 \%$ \\
\hline Foreign fixed income securities & Not aut & orized & $10 \%$ & $20 \%$ \\
\hline Foreign equities & Not aut & orized & $5 \%$ & $10 \%$ \\
\hline Other instruments authorized by the Central Bank & Not aut & orized & $1 \%$ & $5 \%$ \\
\hline Risk hedging operations & Not aut & orized & $10 \%$ & $25 \%$ \\
\hline
\end{tabular}

Source: Ferreiro (2003), pages 138 and 139.

${ }^{a}$ : For 1999 this is a joint limit for all plc shares.

${ }^{b}$ : For 1999 this is a joint limit for all real estate investment fund shares.

c: For 1999 this is included in sub-limit for foreign equity. 
Table 3: Summary statistics of the estimation sample

\begin{tabular}{lc}
\hline \hline & Mean (Standard deviation) \\
\hline Number of people & 8,888 \\
Gender (female) & 0.5 \\
Age when enrolling & 24.66 \\
& $(8.92)$ \\
Age in 2001 & 30.58 \\
& $(9.71)$ \\
Voluntary savings & 0.16 \\
Number of months observed & $(0.37)$ \\
Income in pesos of December 2001/U.S. dollars of December 2001 & 63.94 \\
& $222,552.4 / 332.6$ \\
Time inactive & $(239,173.8) /(354.4)$ \\
Active decisions & 11.85 \\
(as \% of total decisions) & $(13.82)$ \\
\hline \hline Number of changes & 43,648 \\
\hline
\end{tabular}


Table 4: Fraction of observations involving switching behavior by contribution status

\begin{tabular}{l|cccc}
\hline \hline Contribution & Number of & Number of & \multicolumn{2}{c}{$\begin{array}{c}\text { Changes as \% of observations } \\
\text { status }\end{array}$} \\
\hline Returning enrollees & 43,648 & 4,772 & $10.9 \%$ & $15 \%$ \\
Existing enrollees & 298,124 & 7,424 & $2.5 \%$ & $3.3 \%$ \\
\hline \hline
\end{tabular}

The table was constructed using all observations except initial choices. 
Table 5: Effect of changes in income and demographics on the probability of changing

\begin{tabular}{|c|c|c|c|c|c|c|}
\hline & $(1)$ & $(2)$ & $(3)$ & (4) & $(5)$ & $(6)$ \\
\hline \multirow[t]{2}{*}{ Returning } & $0.732^{* * *}$ & & $0.729^{* * *}$ & $0.736^{* * *}$ & $0.744^{* * *}$ & $0.784^{* * *}$ \\
\hline & $(0.01)$ & & $(0.01)$ & $(0.011)$ & $(0.011)$ & $(0.011)$ \\
\hline \multirow[t]{2}{*}{ Increase in income $>10 \%$} & & $0.123^{* * *}$ & 0.013 & $-0.006^{* * *}$ & -0.015 & -0.008 \\
\hline & & $(0.009)$ & $(0.009)$ & $(0.01)$ & $(0.01)$ & $(0.01)$ \\
\hline \multirow[t]{2}{*}{ Age } & & & & & $-0.007 * * *$ & $-0.009^{* * *}$ \\
\hline & & & & & $(0.001)$ & $(0.001)$ \\
\hline \multirow[t]{2}{*}{ Male } & & & & & 0.003 & 0.015 \\
\hline & & & & & $(0.014)$ & $(0.013)$ \\
\hline Has a voluntary & & & & & $0.172^{* * *}$ & $0.151^{* * *}$ \\
\hline savings acocunt & & & & & $(0.015)$ & $(0.014)$ \\
\hline Marginal effect & $10.93 \%$ & & $10.9 \%$ & $10.52 \%$ & $10.59 \%$ & $10.7 \%$ \\
\hline Year fixed effects & No & No & No & Yes & Yes & Yes \\
\hline PFA fixed effects & No & No & No & No & No & Yes \\
\hline $\mathrm{N}$ & 341,772 & 341,772 & 341,772 & 341,772 & 341,772 & 341,769 \\
\hline Pseudo $R^{2}$ & 0.054 & 0.002 & 0.054 & 0.0963 & 0.102 & 0.149 \\
\hline Log Likelihood & $-49,809.5$ & $-52,530.4$ & $-49,808.5$ & $-47,557.7$ & $-47,283.3$ & $-44,755.2$ \\
\hline$\chi^{2}$ & $5,339.9$ & 194.8 & $5,454.1$ & $6,578.3$ & $6,774.3$ & $11,776.5$ \\
\hline
\end{tabular}

Standard errors, clustered at the individual level, in parentheses. ${ }^{* * *} p<0.01$. An observation is an individual-month combination. The dependent variable is equal to one if the individual switched and zero otherwise. Estimation method is by maximum likelihood. The specified model is a probit model. 
Table 6: Mean and standard deviation of excess payment and returns by number of changes

\begin{tabular}{lccc}
\hline \hline \multirow{2}{*}{ Number of changes } & \multicolumn{2}{c}{ Mean excess payment } & Mean real \\
& with vol. savings account & without vol. savings account & annual return \\
\hline 0 & $18.8 \%$ & $12.2 \%$ & $9.01 \%$ \\
1 & $14.2 \%$ & $9.7 \%$ & $9.02 \%$ \\
2 & $14.9 \%$ & $9.1 \%$ & $8.9 \%$ \\
3 & $12.2 \%$ & $9.8 \%$ & $9 \%$ \\
4 & $9.9 \%$ & $9 \%$ & $9.01 \%$ \\
$\geq 5$ & $9.6 \%$ & $9 \%$ & $9.1 \%$ \\
\hline \hline
\end{tabular}

The table was constructed using excess payments and returns after switching for people who actually switched managers.

For people who did not switch, all observations are considered. 
Table 7: Effect of contribution status on excess payment relative to the cheapest alternative, conditional on switching or being a new enrollee (OLS)

\begin{tabular}{lccc}
\hline \hline & $(1)$ & $(2)$ & $(3)$ \\
\hline Returning & $2.426^{* *}$ & 0.619 & 0.807 \\
& $(1.024)$ & $(1.279)$ & $(1.197)$ \\
Existing & $-2.329^{* *}$ & -0.836 & -0.716 \\
& $(0.939)$ & $(0.717)$ & $(0.753)$ \\
\hline Enrollee FE & Yes & Yes & Yes \\
Pension fund FE & No & Yes & Yes \\
Month and Year FE & No & No & Yes \\
\hline Observations & 21,084 & 21,084 & 21,084 \\
$R^{2}$ & 0.253 & 0.286 & 0.287 \\
\hline \hline
\end{tabular}

Robust standard errors in parentheses. ${ }^{* *} p<0.05$.

The dependent variable is excess payment. The ommited category is new enrollees. Regressions include initial choices and changes of pension funds. 
Table 8: Estimated parameters of the structural model

\begin{tabular}{|c|c|c|c|c|c|c|c|}
\hline & & \multicolumn{5}{|c|}{ Past performance measured by } & \multirow{3}{*}{$\begin{array}{c}\text { Initial choices } \\
(6) \\
\end{array}$} \\
\hline & & \multicolumn{2}{|c|}{ Returns } & \multicolumn{2}{|c|}{ Absolute ranking of returns } & \multirow{2}{*}{$\begin{array}{l}\text { Relative ranking of returns } \\
\text { (5) }\end{array}$} & \\
\hline & & (1) & (2) & (3) & (4) & & \\
\hline \multirow[t]{14}{*}{ Decision cost } & Constant & & 3.5425 & & 3.5046 & 3.5062 & \\
\hline & & & $(0.0678)$ & & $(0.068)$ & $(0.068)$ & \\
\hline & Age & & 0.0135 & & 0.0146 & 0.0145 & \\
\hline & & & $(0.0021)$ & & $(0.0021)$ & $(0.0021)$ & \\
\hline & Gender & & -0.0207 & & -0.0205 & -0.0211 & \\
\hline & & & $(0.0338)$ & & $(0.0338)$ & $(0.0338)$ & \\
\hline & Income & & -0.004 & & -0.0039 & -0.0039 & \\
\hline & & & (0.0005) & & $(0.0005)$ & $(0.0005)$ & \\
\hline & Voluntary savings & & -0.3888 & & -0.3935 & -0.3915 & \\
\hline & & & $(0.0356)$ & & $(0.0356)$ & $(0.0356)$ & \\
\hline & Regulation & & 0.5076 & & 0.5198 & 0.5227 & \\
\hline & & & $(0.0372)$ & & $(0.0373)$ & $(0.0374)$ & \\
\hline & $\sigma^{D}$ & & 0.0385 & & 0.0392 & 0.0369 & \\
\hline & & & $(0.0768)$ & & $(0.0761)$ & $(0.0761)$ & \\
\hline \multirow[t]{14}{*}{ Enrollment cost } & Constant & & 1.1608 & & 1.1727 & 1.1677 & \\
\hline & & & $(0.0838)$ & & $(0.0838)$ & $(0.0837)$ & \\
\hline & Age & & 0.0134 & & 0.013 & 0.0131 & \\
\hline & & & $(0.0027)$ & & $(0.0027)$ & $(0.0027)$ & \\
\hline & Gender & & 0.0044 & & 0.0036 & 0.0042 & \\
\hline & & & $(0.0413)$ & & $(0.0414)$ & $(0.0413)$ & \\
\hline & Income & & -0.0044 & & -0.0047 & -0.0047 & \\
\hline & & & $(0.0007)$ & & $(0.0007)$ & $(0.0007)$ & \\
\hline & Voluntary savings & & 0.157 & & 0.1639 & 0.1636 & \\
\hline & & & $(0.043)$ & & $(0.043)$ & $(0.043)$ & \\
\hline & Regulation & & 0.4061 & & 0.4215 & 0.4343 & \\
\hline & & & $(0.0468)$ & & $(0.0469)$ & $(0.047)$ & \\
\hline & $\sigma^{E}$ & & 0.0669 & & 0.0706 & 0.0665 & \\
\hline & & & $(0.0881)$ & & $(0.0877)$ & $(0.0876)$ & \\
\hline \multirow[t]{8}{*}{ Marginal utility of income } & Constant & 1.8291 & 4.2712 & 1.7654 & 4.1663 & 4.2174 & 5.8039 \\
\hline & & $(0.1606)$ & $(0.3302)$ & $(0.1599)$ & $(0.3305)$ & $(0.3301)$ & $(0.8243)$ \\
\hline & Age & -0.0806 & -0.1019 & -0.0821 & -0.0984 & -0.1017 & -0.0445 \\
\hline & & $(0.0045)$ & $(0.0097)$ & $(0.0045)$ & $(0.0098)$ & $(0.0097)$ & $(0.0228)$ \\
\hline & Gender & -0.7469 & -0.7478 & -0.7187 & -0.7393 & -0.7413 & -1.5371 \\
\hline & & $(0.0771)$ & $(0.1602)$ & $(0.0768)$ & $(0.1603)$ & $(0.1602)$ & $(0.4289)$ \\
\hline & $\sigma^{\alpha}$ & 0.6028 & 0.4084 & 0.6378 & 0.4352 & 0.4341 & 3.8736 \\
\hline & & $(0.0859)$ & $(0.1892)$ & $(0.0845)$ & $(0.1894)$ & $(0.1881)$ & $(0.4763)$ \\
\hline \multirow[t]{10}{*}{ Marginal utility of returns } & Constant & -0.0138 & -0.0322 & -0.0291 & -0.0451 & -0.4273 & -0.0259 \\
\hline & & $(0.0043)$ & $(0.0094)$ & $(0.0024)$ & $(0.0059)$ & $(0.0834)$ & $(0.0129)$ \\
\hline & Age & 0.0006 & 0.0006 & 0.0002 & 0.0013 & 0.0158 & 0.0002 \\
\hline & & $(0.0001)$ & $(0.0003)$ & $(0.0001)$ & $(0.0002)$ & $(0.0027)$ & $(0.0004)$ \\
\hline & Gender & 0.0004 & 0.0035 & -0.0142 & -0.0042 & -0.0667 & 0.0072 \\
\hline & & $(0.0024)$ & $(0.0048)$ & $(0.0013)$ & $(0.003)$ & $(0.0429)$ & $(0.0078)$ \\
\hline & Income & 0.0001 & $-3.56 \mathrm{E}-005$ & 0.0011 & 0.0005 & 0.0064 & 0.0003 \\
\hline & & $(3.93 \mathrm{E}-005)$ & $(0.0001)$ & $(2.86 \mathrm{E}-005)$ & $(4.56 \mathrm{E}-005)$ & $(0.0006)$ & $(0.0001)$ \\
\hline & $\sigma^{\beta}$ & 0.0039 & 0.0019 & 0.0084 & 0.0003 & 0.013 & 0.0088 \\
\hline & & $(0.0031)$ & $(0.0055)$ & $(0.0016)$ & $(0.0042)$ & $(0.0548)$ & $(0.0097)$ \\
\hline McFadden's Pseudo $R^{2}$ & & 0.2994 & 0.8899 & 0.3004 & 0.8901 & 0.89 & 0.32 \\
\hline Number of observations & & 350,660 & 350,660 & 350,660 & 350,660 & 350,660 & 8,888 \\
\hline
\end{tabular}

Asymptotically robust standard errors in parentheses. PFA fixed effects included in all specifications. The dependent variable is an indicator that is equal to one for the chosen PFA and zero for the rest. Estimation is via Simulated Maximum Likelihood. 
Table 9: Model fit: Choice probabilities (percent)

\begin{tabular}{l|cc||c|cc||c|cc}
\hline \hline \multicolumn{4}{c||}{ Model estimated model with all the data } & \multicolumn{2}{c}{$\begin{array}{c}\text { Model estimated with } \\
\text { only initial choices }\end{array}$} \\
PFA choices & Data & Predicted & PFA & Data & Predicted & PFA & Data & Predicted \\
\hline 20 & 36.7 & 36.6 & 20 & 37.1 & 25.8 & 20 & 37.1 & 37.2 \\
12 & 24.6 & 24.5 & 22 & 22.5 & 16.3 & 22 & 22.5 & 22.5 \\
22 & 18.1 & 18.1 & 12 & 20.5 & 18.3 & 12 & 20.5 & 20.4 \\
23 & 7.1 & 7.1 & 23 & 4.7 & 8.2 & 23 & 4.7 & 4.7 \\
7 & 5.9 & 5.8 & 19 & 3.4 & 7.3 & 19 & 3.4 & 4.3 \\
\hline \hline
\end{tabular}

The first six columns of the table were constructed using the estimated parameters of the fourth specification in table 8 . The last three columns used the estimated parameters of the sixth specification in table 8

Table 10: Effect of switching costs and entry on equilibrium prices

\begin{tabular}{|c|c|c|c|c|}
\hline & $\mathrm{T}=1$ & $\mathrm{~T}=2$ & $\mathrm{~T}=3$ & Discounted profits ${ }^{a}$ \\
\hline Full inertia, returning enrollees, and entry & $2 \%$ & $9.5 \%$ & $17.5 \%$ & - \\
\hline No inertia & $7 \%$ & $7 \%$ & $7 \%$ & $70.1 \%$ \\
\hline Policy I: Eliminate the enrollment cost & $5 \%$ & $9 \%$ & $13.5 \%$ & $90.1 \%$ \\
\hline Policy II: Eliminate the decision cost & $3.5 \%$ & $6.5 \%$ & $8.5 \%$ & $67.2 \%$ \\
\hline Regulation: Mandatory default option for new enrollees ${ }^{b}$ & $0.6 \%$ & $9 \%$ & $11.96 \%$ & $75.9 \%$ \\
\hline
\end{tabular}


Table 11: Effect of switching costs and entry on equilibrium prices

\begin{tabular}{|c|c|c|c|c|c|c|}
\hline \multirow[b]{2}{*}{ Prices } & & \multicolumn{5}{|c|}{ Price differential in $t=1\left(p_{1}-p_{2}\right)$} \\
\hline & & -0.5 & -0.05 & 0 & 0.05 & 0.5 \\
\hline \multirow[t]{2}{*}{ Full inertia, returning enrollees, and entry } & Firm 1 & 0.16 & 0.11 & 0.095 & 0.07 & 0.095 \\
\hline & Firm 2 & 0.095 & 0.07 & 0.095 & 0.11 & 0.16 \\
\hline \multirow[t]{2}{*}{ No inertia } & Firm 1 & 0.07 & 0.07 & 0.07 & 0.07 & 0.07 \\
\hline & Firm 2 & 0.07 & 0.07 & 0.07 & 0.07 & 0.07 \\
\hline Regulation: Mandatory default option & Firm 1 & 0.17 & 0.095 & 0.09 & 0.08 & 0.135 \\
\hline for new enrolees & Firm 2 & 0.135 & 0.08 & 0.09 & 0.095 & 0.17 \\
\hline Profits relative to full inertia & & -0.5 & -0.05 & 0 & 0.05 & 0.5 \\
\hline \multirow[t]{2}{*}{ Full inertia, returning enrollees, and entry } & Firm 1 & $105 \%$ & $113 \%$ & $95 \%$ & $111 \%$ & $105 \%$ \\
\hline & Firm 2 & $105 \%$ & $111 \%$ & $95 \%$ & $113 \%$ & $105 \%$ \\
\hline \multirow[t]{2}{*}{ No inertia } & Firm 1 & $19 \%$ & $24 \%$ & $24 \%$ & $36 \%$ & $39 \%$ \\
\hline & Firm 2 & $39 \%$ & $36 \%$ & $24 \%$ & $24 \%$ & $19 \%$ \\
\hline Regulation: Mandatory default option & Firm 1 & $100 \%$ & $80 \%$ & $76 \%$ & $106 \%$ & $100 \%$ \\
\hline for new enrolees & Firm 2 & $84 \%$ & $106 \%$ & $76 \%$ & $80 \%$ & $84 \%$ \\
\hline
\end{tabular}

Prices and profits correspond to those obtained in the second period for different first-period price differentials.

Table 12: Effect of switching costs and entry of a new manager on equilibrium prices:

\begin{tabular}{lcc}
\hline \hline & Incumbents & Entrant \\
\hline No regulation & $14 \%$ & $7.5 \%$ \\
With regulation $^{a}$ & $14.5 \%$ & $9 \%$ \\
\hline \hline${ }^{a}:$ All prices reported here correspond to expected prices according to the probability distributions \\
of the mixed strategy equilibrium computed with Gambit, software elaborated by McKelvev. McLennan and Turocv $(\underline{2010})$.
\end{tabular}

Table 13: Welfare decomposition: Effect of changes in prices and switching costs on welfare

\begin{tabular}{lcccc}
\hline \hline & No inertia & No decision cost & No enrollment cost & Regulation \\
\hline Mean change in consumer surplus & $+4.62 \%$ & $+4.98 \%$ & $+0.61 \%$ & $+2.6 \%$ \\
Change in profits & $-29.3 \%$ & $-32.8 \%$ & $-9.1 \%$ & $-24.1 \%$ \\
\hline Change in total surplus & $+1.75 \%$ & $+1.68 \%$ & $+0.5 \%$ & $+0.91 \%$ \\
\hline \hline
\end{tabular}




\section{Figures}

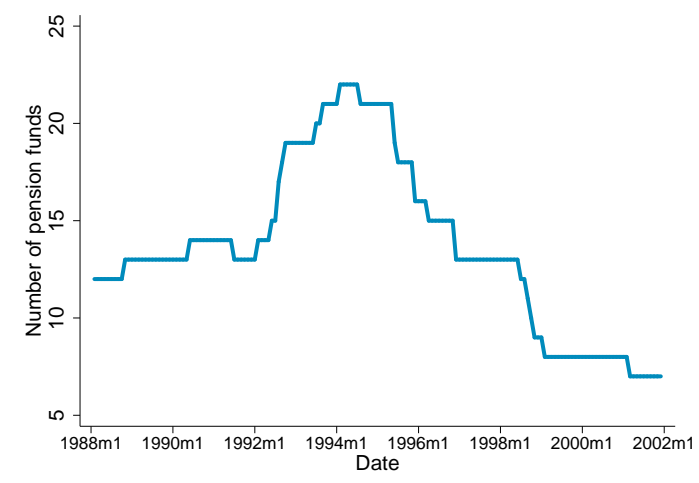

(a) Number of PFAs

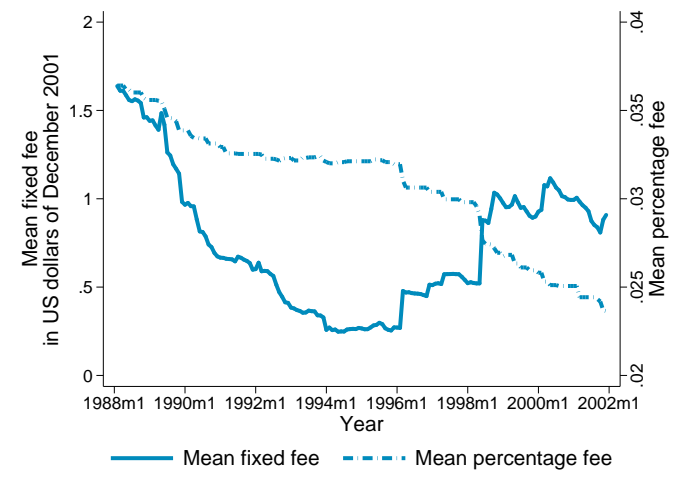

(b) Fees

Figure 1: Number of PFAs and fees over time

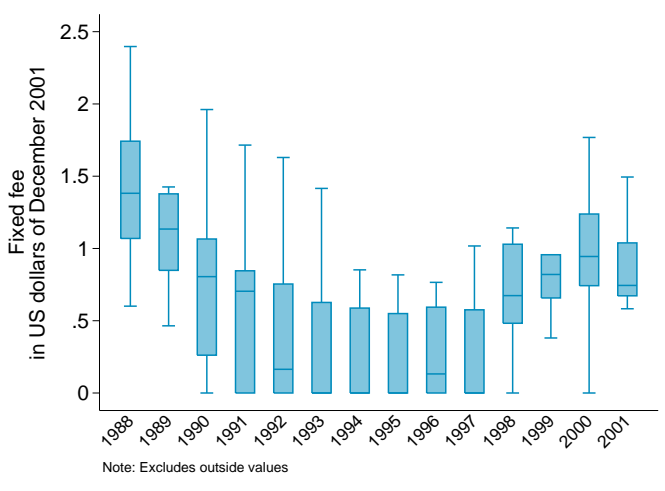

(a) Fixed fee

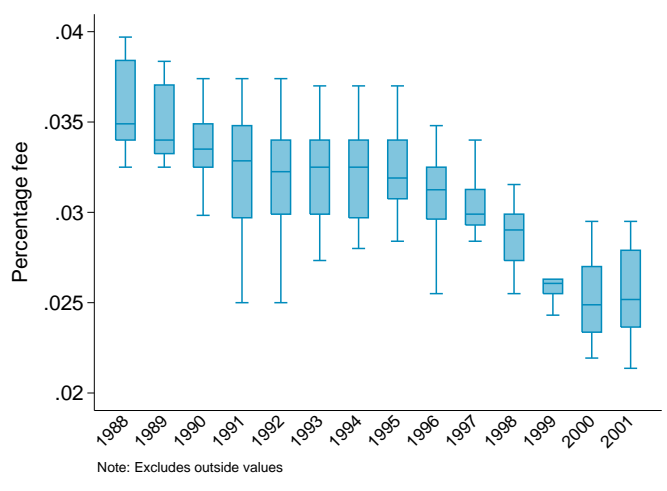

(b) Percentage fee

Figure 2: Distribution of fees over time 


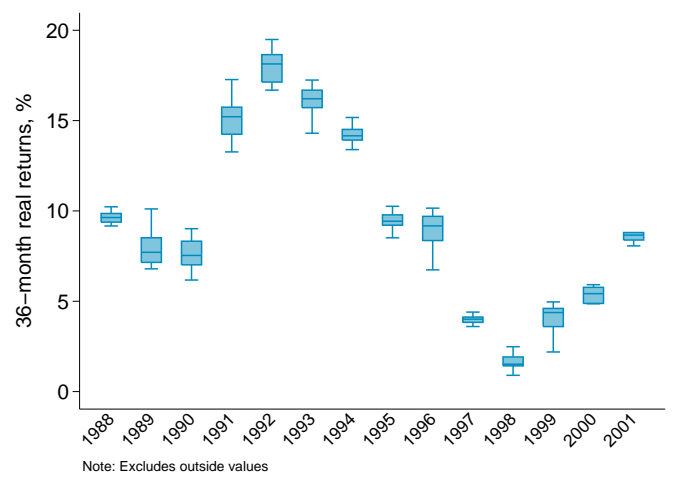

Figure 3: Distribution of realized returns by year (36-month real returns)

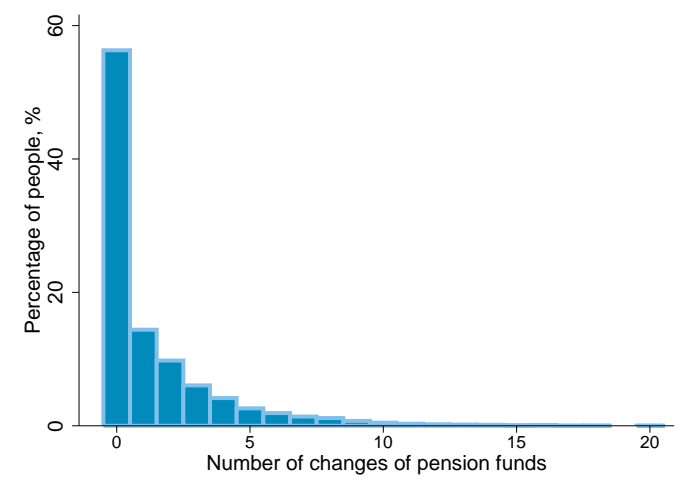

Figure 4: Number of changes per person

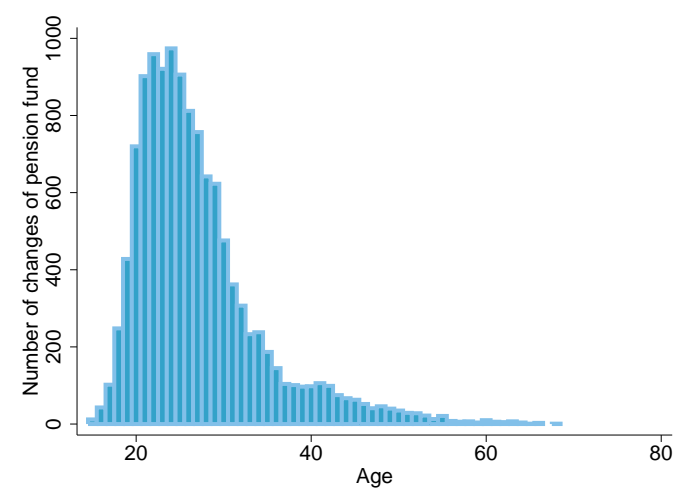

(a) Number of changes by age

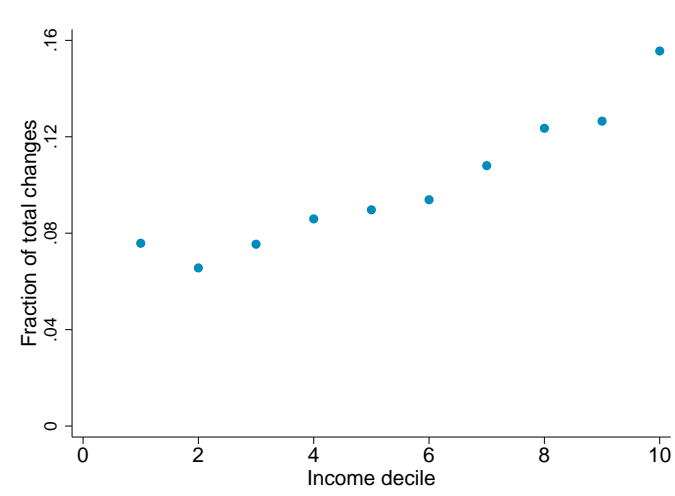

(b) Number of changes by income deciles

Figure 5: Number of changes by age and income 


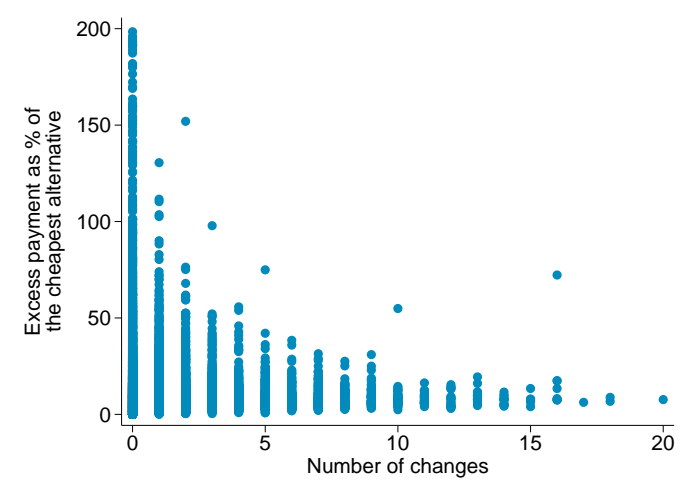

(a) Excess payment

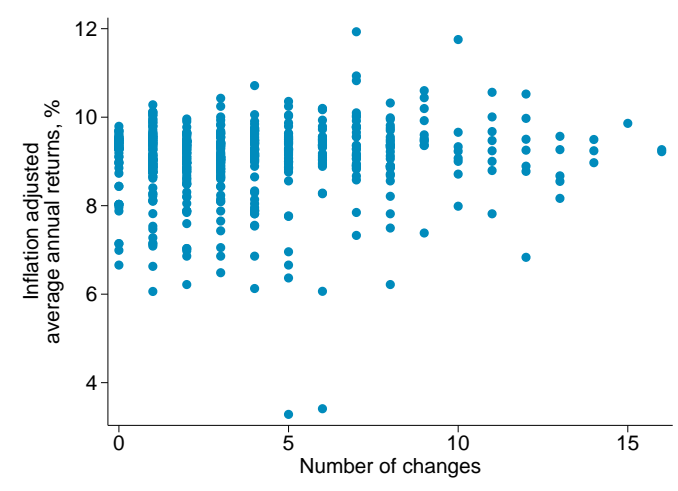

(b) Returns

Figure 6: Fees and returns by number of changes

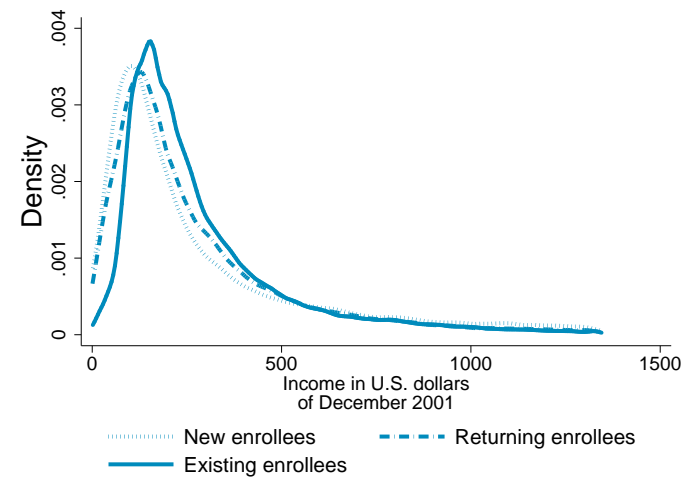

(a) Income (the graph excludes $3.5 \%$ of observa-

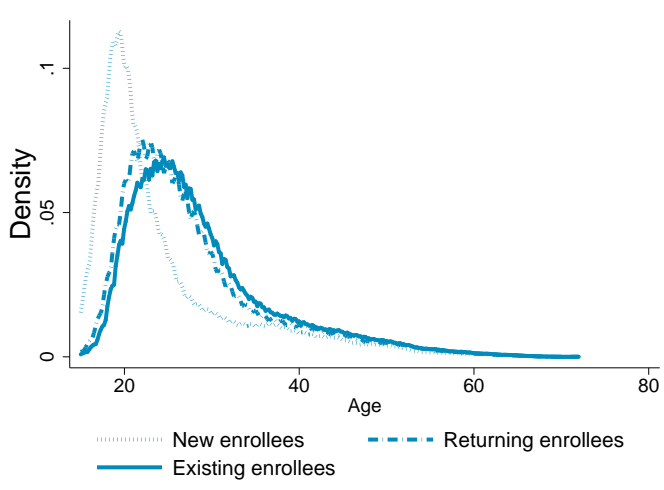

(b) Age tions that consist of people who earned more than $\$ 1,350$ U.S. dollars of December 2001)

Figure 7: Density of income and age across groups 


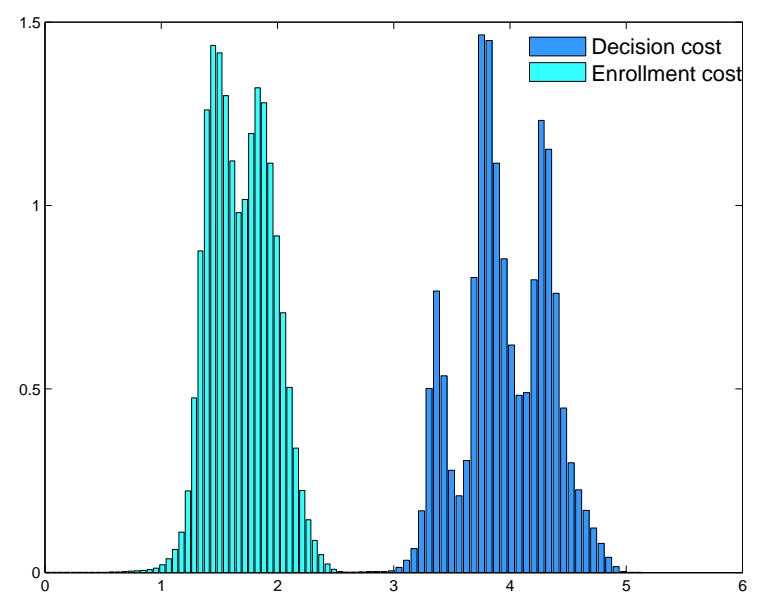

Figure 8: Frequency distribution of switching costs, by component
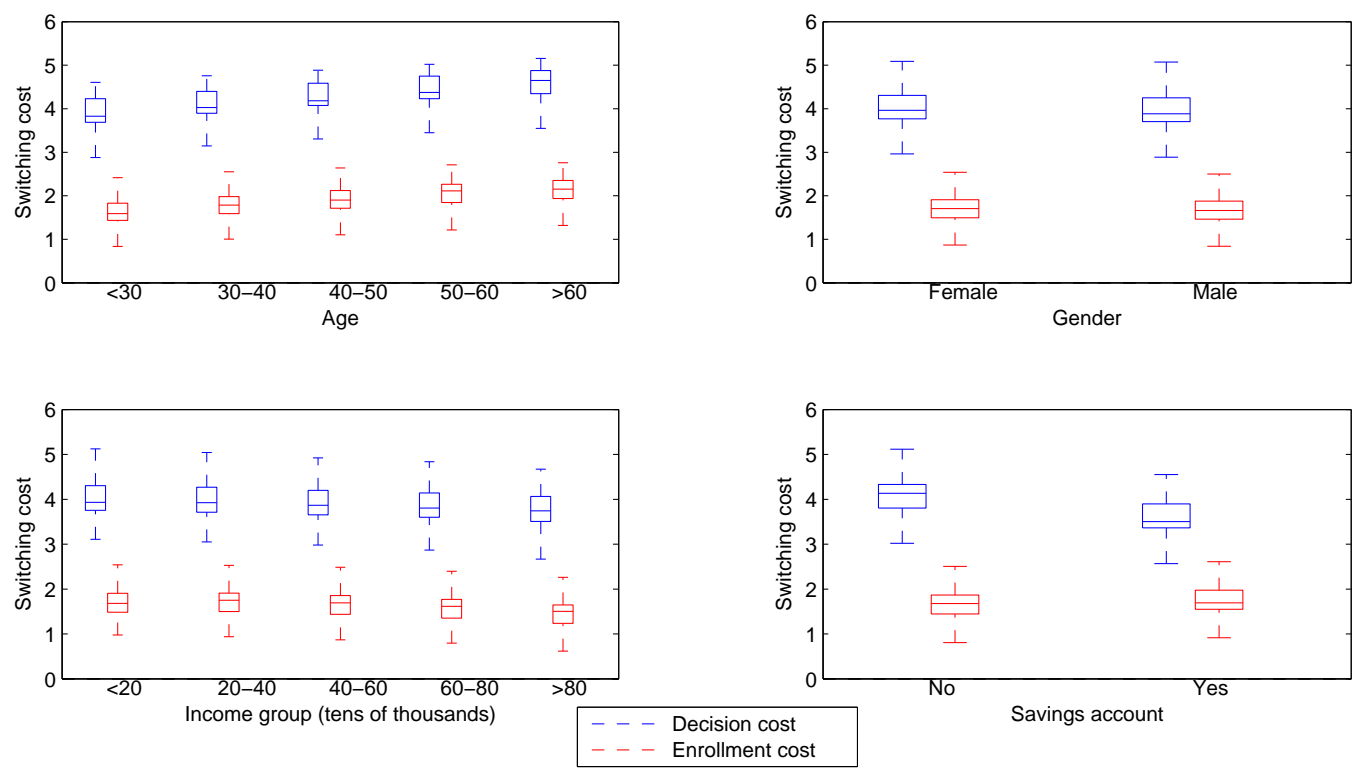

Figure 9: Distribution of switching costs by observables 


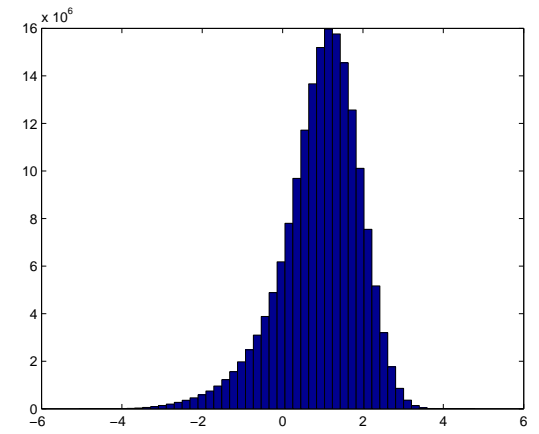

(a) Distribution of $\alpha_{i t}$

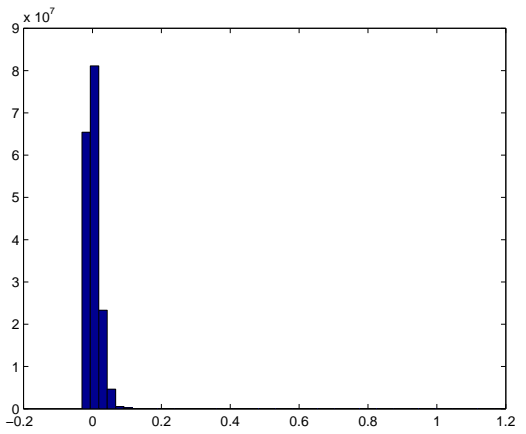

(b) Distribution of $\beta_{i t}$

Figure 10: Frequency distribution of taste coefficients

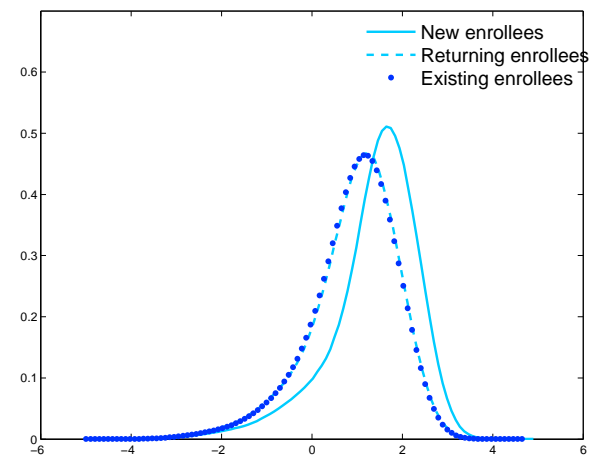

(a) Status

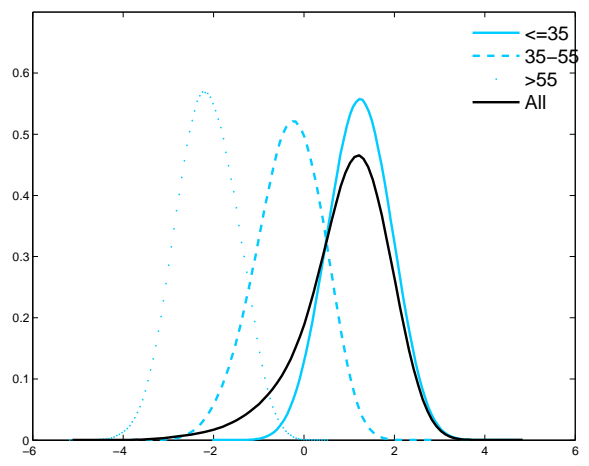

(b) Age groups

Figure 11: Density of $\alpha_{i t}$ by status and age groups 


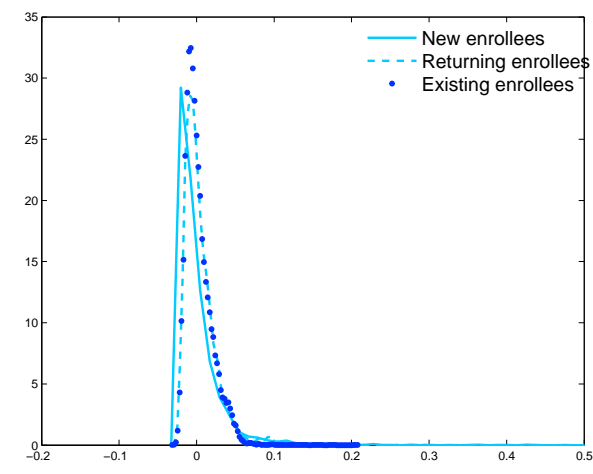

(a) Status

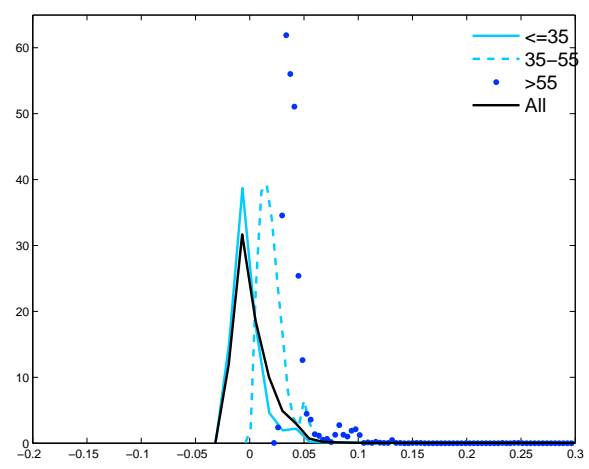

(b) Age groups

Figure 12: Density of $\beta_{i t}$ by status and age groups. In both figures the right tail reported in figure $10(\mathrm{~b})$ was cut from the plot, though not from the calculations 